San Jose State University

SJSU ScholarWorks

Master's Theses

Master's Theses and Graduate Research

1994

\title{
Gender differences in condom use among sexually active undergraduate college students
}

Jean M. Breny Bontempi

San Jose State University

Follow this and additional works at: https://scholarworks.sjsu.edu/etd_theses

\section{Recommended Citation}

Bontempi, Jean M. Breny, "Gender differences in condom use among sexually active undergraduate college students" (1994). Master's Theses. 734.

DOI: https://doi.org/10.31979/etd.c4e3-pcwq

https://scholarworks.sjsu.edu/etd_theses/734

This Thesis is brought to you for free and open access by the Master's Theses and Graduate Research at SJSU ScholarWorks. It has been accepted for inclusion in Master's Theses by an authorized administrator of SJSU ScholarWorks. For more information, please contact scholarworks@sjsu.edu. 


\section{INFORMATION TO USERS}

This manuscript has been reproduced from the microfilm master. UMI films the text directly from the original or copy submitted. Thus, some thesis and dissertation copies are in typewriter face, while others may be from any type of computer printer.

The quality of this reproduction is depemdent upon the quality of the copy submitted. Broken or indistinct print, colored or poor quality illustrations and photographs, print bleedthrough, substandard margins, and improper alignment can adversely affect reproduction.

In the unlikely event that the author did not send UMI a complete manuscript and there are missing pages, these will be noted. Also, if unauthorized copyright material had to be removed, a note will indicate the deletion.

Oversize materials (e.g., maps, drawings, charts) are reproduced by sectioning the original, beginning at the upper left-hand corner and continuing from left to right in equal sections with small overlaps. Each original is also photographed in one exposure and is included in reduced form at the back of the book.

Photographs included in the original manuscript have been reproduced xerographically in this copy. Higher quality $6 "$ " $\times 9$ " black and white photographic prints are available for any photographs or illustrations appearing in this copy for an additional charge. Contact UMI directly to order.

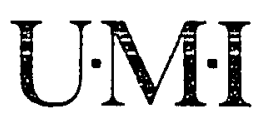

University Microfilms internatıona!

A Bell \& Howell Information Company

300 North Zeeb Road. Ann Arbor. Ml 48106-1346 USA

$313: 761-4700 \quad 800 / 521-0600$ 
-2... 
Order Number 1958158

Gender differences in condom use among sexually active undergraduate college students

Breny Bontempi, Jean Marie, M.P.H.

San Jose State University, 1994 
$\div$ 


\title{
GENDER DIFFERENCES IN CONDOM USE \\ AMONG SEXUALLY ACTIVE \\ UNDERGRADUATE COLLEGE STUDENTS
}

\author{
A Thesis \\ Presented to \\ The Faculty of the Department of Health Science \\ San Jose State University \\ in Partial Fulfillment \\ of the Requirements for the Degree \\ Master of Public Health
}

by

Jean M. Breny Bontempi

May, 1994 
(C) May, 1994

\section{ALL RIGHTS RESERVED}

Jean M. Breny Bontempi 
APPROVED FOR THE DEPARTMENT OF HEALTH SCIENCE

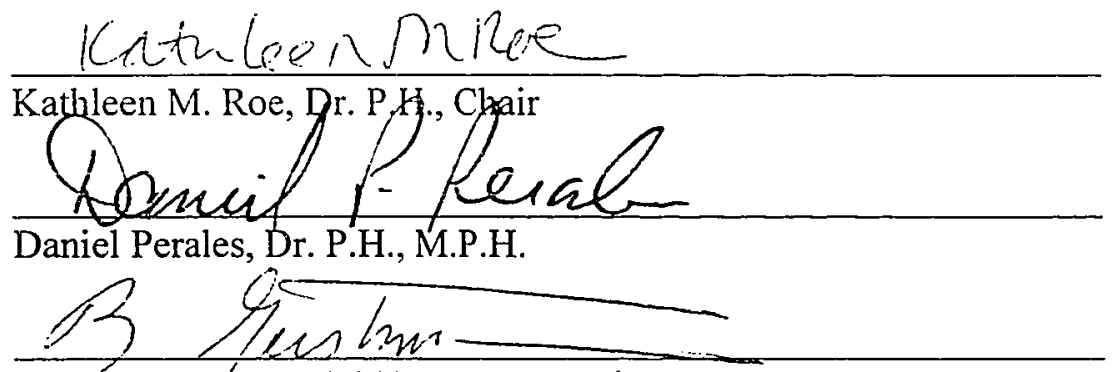

B. Burt Gerstman, D.V.M., M.P.H., Ph.D.

APPROVED FOR THE UNIVERSITY

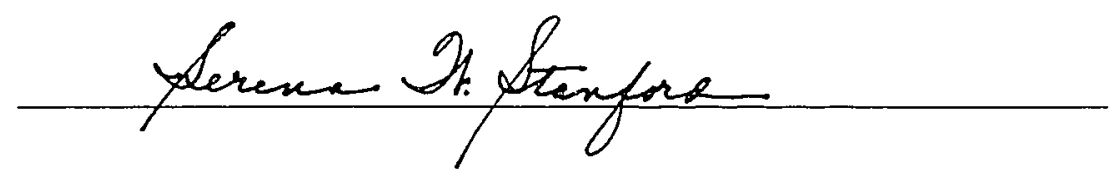




\title{
ABSTRACT \\ GENDER DIFFERENCES IN CONDOM USE AMONG SEXUALLY ACTIVE UNDERGRADUATE COLLEGE STUDENTS
}

\author{
by Jean M. Breny Bontempi
}

This thesis addresses the problem of inconsistent condom use by sexually active undergraduate college students. Gender differences related to their attitudes and behaviors regarding condoms were explored. An original questionnaire was developed and administered to 246 undergraduate Health Science and Engineering students at San Jose State University. A total of 165 non-married, sexually active college students were included in the final sample.

Chi-square analysis and frequency tests were used. Results revealed several statistically significant gender differences. Males reported previous condom use significantly more than females but would have sex with a potential partner without a condom. Females had previously talked with a partner about condoms significantly more than males even though their reported use was low. Being in a self-identified monogamous relationship was a significant predictor of condom use among females. A majority of the sample felt that using condoms did protect them from AIDS and sexually transmitted diseases. 


\section{ACKNOWLEDGMENTS}

To Kathleen M. Roe, Dr. P. H. for her endless support and energy as my thesis advisor. Without Katily's enthusiasm, intelligence, and confidence in me I would not have gotten through this endeavor. Thank you for being my mentor.

To Daniel Perales, Dr. P. H. for his commitment and dedication to this thesis research and for coming to San Francisco on his day off for an advising session.

To Bud Gerstman, D. V. M., M. P. H., Ph. D. for sharing his appreciation of quantitative research and assisting me with data analysis on this thesis.

To the 246 San Jose State University students who made this research possible through their participation as my study sample. Thank you for your time and honesty.

To the Health Science Department at San Jose State University, thank you for a wonderful graduate school experience.

Finally, to my husband, Chris, who has been my backbone throughout this entire effort. Thank you for the love, support, and encouragement I needed to complete this thesis research.

\section{DEDICATION}

I dedicate this thesis research to my parents, Angie and Craig Breny, who are two of my favorite people in the entire world. Without their love I would never have had the strength and confidence to be where I am today. I love you. 
TABLE OF CONTENTS

Chapter

Page

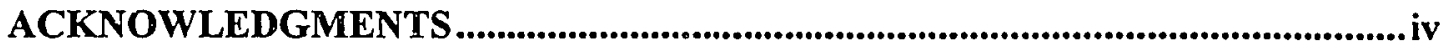

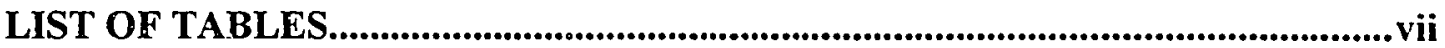

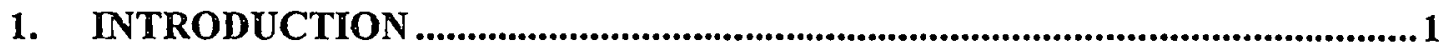

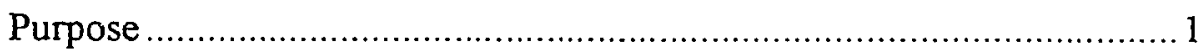

Statement of the Problem................................................................ 2

Research Procedures.......................................................................... 5

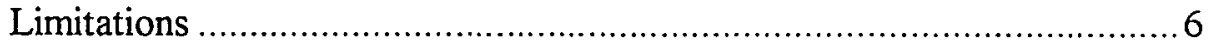

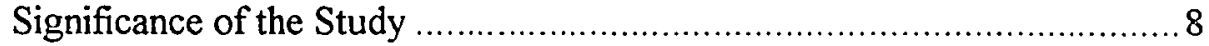

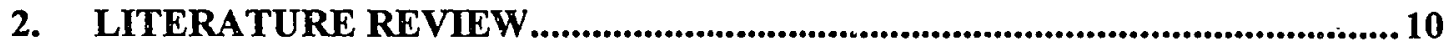

Theoretical Framework................................................................... 10

Health Belief Model ........................................................... 10

Social Learning Theory and Self-Efficacy ................................ 12

Gender Role Theories .................................................... 18

Condom Use Studies .............................................................. 21

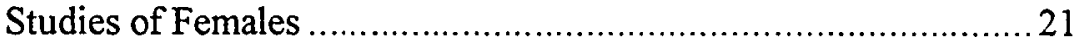

Studies of Males......................................................... 25

Male and Female Studies................................................26

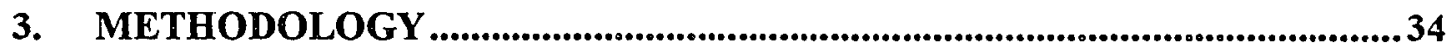

Overall Research Questions .......................................................... 34

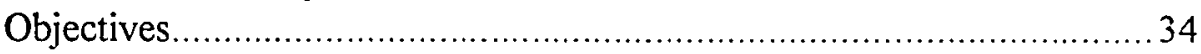

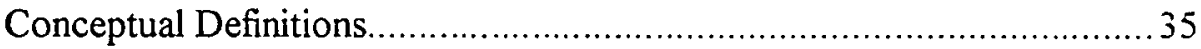

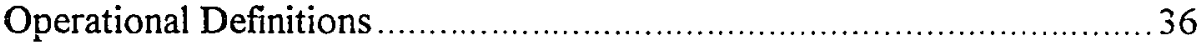

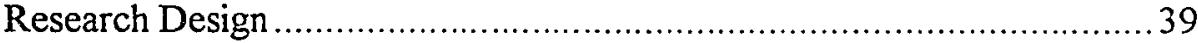

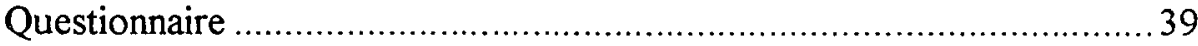

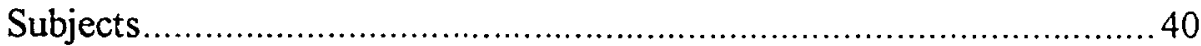

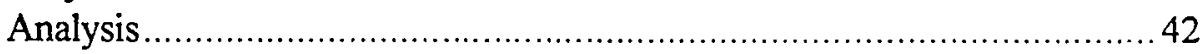

Methodological Assumptions................................................ 43

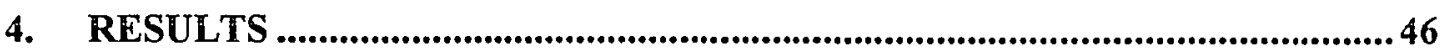

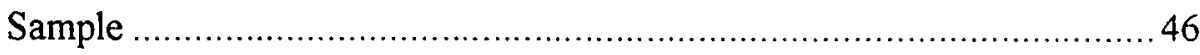

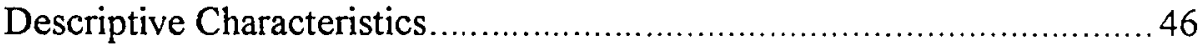

Condom Knowledge and Attitudes ............................................. 48

Age of First Sexual Experience ........................................................ 50

Personal Experience with Condoms ............................................. 52

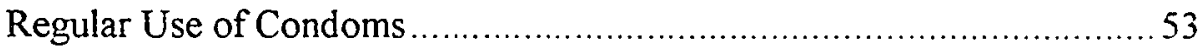




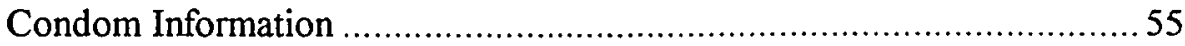

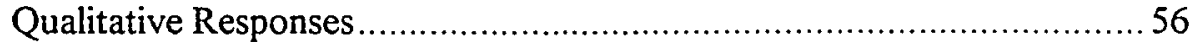

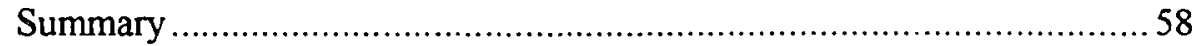

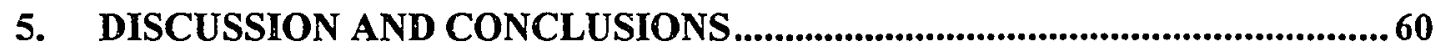

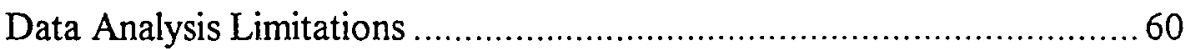

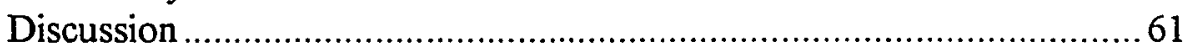

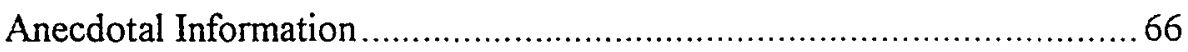

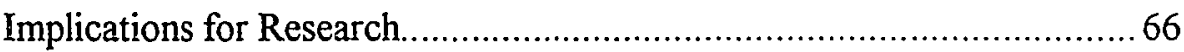

Implications for College Health Education Practice...........................69

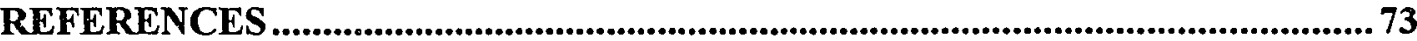

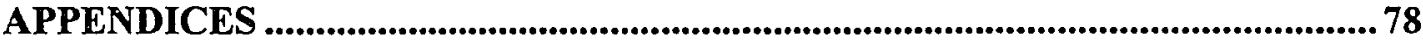

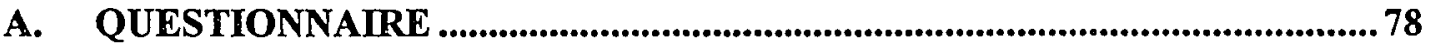

B. SJSU HUMAN SUBJECTS-INSTITUTIONAL REVIEW BOARD

ACCEPTANCE LETTER........................................................................................... 82

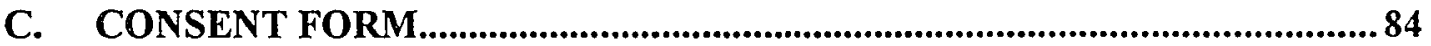

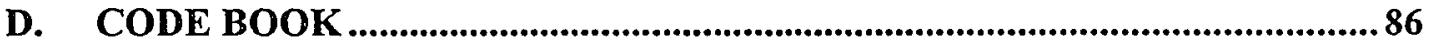




\section{LIST OF TABLES}

Table Page

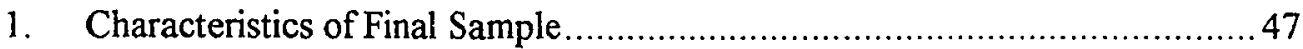

2. Condom Knowledge and Attitude Responses by Gender........................49

3. Age of First Sexual Experience by Gender .......................................... 51

4. Age of Initial Condom Use by Gender .................................................5 51

5. Gender Differences in Experience with Condoms................................ 52

6. Use of Condoms Over the Past Year by Gender .................................... 54

7. Single vs. Monogamous Females and Regular Condom Use ...................55 


\section{Chapter 1}

\section{INTRODUCTION}

\section{Purpose}

Young adults, including college students, are a population at risk for Human Immunodeficiency Virus (HIV) and other sexually transmitted diseases (STDs). Health care providers and policy makers are increasingly aware that this population is at risk (Bell \& Holmes, 1984; Boyer \& Kegeles, 1991; DiClemente, 1990; Gayle et al., 1990) and have identified education as essential for prevention (Rickert, Gottleib, \& Jay, 1990; Turner, Korpita, Mohn, \& Hill, 1993).

Research indicates that while condoms offer some protection against sexually transmitted diseases (Conant, Spicer, \& Smith, 1984) including HIV, many college students do not use condoms regularly (DeBuono, Zinner, Daamen, \& MicCormack, 1990; MacDonald et al., 1990; Turner et al., 1993). This study examined attitudes and behaviors associated with condoms and explored reasons for previously reported patterns of condom use among undergraduate college students. Specifically, the purpose of this research was to determine if sexually active young males use condoms on a more regular basis than do sexually active young females, and if so, why. 


\section{Statement of the Problem}

The prevalence of HIV and other STDs among young people is alarmingly high and rising. A recent Centers for Disease Control and Prevention study of 19 college campuses across the country found an HIV seroprevalence rate of .20\% (Gayle et al., 1990). Other epidemiological studies indicate that the prevalence of syphilis and gonorrhea is highest among 15-24 year olds. In the 15-19 year old age group, gonorrhea prevalence is highest among females, at $1,071.5$ cases per 100,000 population, compared to 916.5 among males. Among males and females in the 20-24 year age group, the prevalence rates are 1,092.1 and 892.9 respectively (Division of STD/HIV Prevention, 1992). In San Francisco, more than half of the cases of gonorrhea, syphilis, and chlamydia occur in the 15-19 year old age group (San Francisco Department of Public Health, 1992).

As of March 15, 1994, a total of 339,250 cases of Acquired Immunodeficiency Syndrome (AIDS) had been reported in the United States (San Francisco AIDS Foundation, personal communication, March 26, 1994). A total of 1,528 AIDS cases among 13-19 year olds and 13,552 cases among 20-24 year olds were reported in the United States as of December 31, 1993 (Centers for Disease Control and Prevention, 1993). Undergraduate college students, generally in these age groups, are considered a population at risk for HIV and other STDs because of their high levels of sexual activity and potential for multiple sexual partners (Koop, 1986).

Although safer sex techniques, including the use of condoms at every sexual encounter, can reduce the risk of HIV and STDs (Feldblum \& Fortney, 1988), research 
suggests that college students are not using condoms regularly (DeBuono et al., 1990; MacDonald et al., 1990). The research further suggests that females use condoms in their sexual encounters less frequently than do males (Collins, Holtzman, Kann, \& Kolbe, 1993; MacDonald et al., 1990). In their study of college students, Hawkins, Hawkins, Ellis, and Ryan (1993) found that when asked about frequency of condom use, $36 \%$ of the sexually active females reported having never used condoms while only $24 \%$ of the sexually active males responded similarly. Collins et al. (1993) examined predictors for condom use among high school students with four or more sexual partners. Their results indicated that $53 \%$ of males used condoms with multiple partners compared to just $29 \%$ of females.

While few studies have focused specifically on gender differences (Carroll, 1991; Hodges, Leavy, Swift, \& Gold, 1992), several studies examining other predictors of condom use found gender differences among their results. Knowledge of AIDS and frequency of condom use (Carroll, 1991); assertive and aggressive behavior in response to talking to partners about safer sex (Yesmont, 1992); communication, knowledge of contraceptive methods, and self-esteem between sexual partners (Burger \& Inderblitzen, 1985); self-efficacy in negotiating condom use with sexual partners (Brafford \& Beck, 1991; O'Leary, Goodhart, Jemmott, \& Boccher-Lattimore, 1992); the central elements of the Health Belief Model (DiClemente et al., 1992); and self-efficacy theory (BasenEngquist, 1992; Brien, Thomas, Mahoney, \& Wallnau, 1994) have all been studied as predictors for condom use and safer sex behaviors among college students. Many of these 
studies found significant gender differences in condom use but the reasons behind these differences were not explored in detail.

Research with both male and female populations has addressed predictors of condom use and safer sex behaviors. A study with male detainees at a correctional institute in Florida (Elfenbein, Weber, \& Grob, 1991) suggests that there were several motives behind the men's reported condom use. Almost $64 \%$ of those who used condoms said they did so to prevent disease and $30 \%$ said it was to prevent pregnancy. Interestingly, $54 \%$ of those who did not use condoms gave no specific reason, $23 \%$ indicated that they did not use condoms because they were in a monogamous relationship, $9 \%$ expressed dissatisfaction with condoms, and $5 \%$ indicated lack of condom availability (Elfenbein et al., 1991).

In a study with 151 female college students, Radius, Joffe, and Gall (1991) found that women who used oral contraceptives were more informed about safer sex behaviors than women who used diaphragms or condoms. The study also found that as many as 9$12 \%$ of female respondents believed that withdrawal of the penis before ejaculation would decrease their STD risk. All of the women reported that condoms protect against the risk of contracting STDs. However, the women who used oral contraceptives were not as aware as the women who used a barrier birth control method that condoms could reduce the risk of HIV.

In their study of college health behaviors, Covin, Lovato, Patrick, and Donovan (1993) found that among their California sample, $49 \%$ reported using condoms at their 
last sexual encounter. A total of $60 \%$ reported receiving condom information from brochures or pamphlets on their campuses. These findings suggest that campus-based student health services may be an important source of condom education.

In summary, the literature raises interesting questions regarding college students' attitudes and behaviors associated with condom use. The increasing incidence of AIDS and STDs among their broader age cohort suggests the need for effective reproductive health education among the college population. Awareness of STDs and HIV risk, the availability of condoms, students' self-efficacy, and their proper use of condoms are vital to the health of these young people. Understanding the reasons behind the attitudes and behaviors towards condoms and related gender differences among undergraduate college students is important.

\section{Research Procedures}

This study used a cross-sectional research design to collect descriptive data regarding college students' attitudes and behaviors regarding condoms. Data collection was done through an anonymous survey of San Jose State University students enrolled in Health Science and Engineering undergraduate classes.

The original questionnaire contained nine demographic questions, eight Likert-type scale questions regarding attitudes and knowledge about condoms, 12 questions pertaining to the participants' sexual activity, and three questions addressing perceived effectiveness 
of condoms in preventing disease transmission and pregnancy. The participants also were asked about their previous safer sex education.

Students were surveyed in their classrooms, during a regularly scheduled class session. Participants were invited to choose free condoms when they turned in their questionnaires. Condoms were purchased at the University's Health Services Condom Co-op and all participants received information about this service. Participants were given the opportunity to receive results of the study by providing the researcher with their names and addresses on a separate postcard.

\section{Limitations}

There were several limitations to this study due to research design, scope of the questionnaire, and sampling bias. These limitations were acknowledged before data collection.

Due to the quantitative nature of this study, operationalized variables were limited to preconceived indicators of attitudes and behaviors regarding condoms. In the interest of keeping the questionnaire short, only the most salient and promising variables from previous research were included. This methodological approach is consistent with much of the previous research on this subject, which has most often used simple questionnaires for data collection. To further explore the complexities of condom use, open-ended interviews might be more appropriate. Time and budget constraints did not allow for qualitative inquiry in this thesis research. However, future qualitative studies using 
interviews with college-âged men and women will allow key variables to be addressed and understood in greater detail.

The correct use of a condom is an important component of safer sex and STD prevention. The scope of the instrument developed for this study precluded exploration of respondents' awareness of correct--and incorrect--condom use. It is possible that student respondents may not know some of the key components of effective condom usage, such as how to remove used condoms, the importance of water-based lubricants, and the use of condoms for anal, oral, and vaginal intercourse. Determining the level of correct usage will be important in future research efforts since incorrect use decreases the potential protection of a condom.

A third limitation regards the accuracy of self-reported sexual behaviors. Respondents may have misunderstood the wording of particular items in the questionnaire. Because the students were in classrooms while completing the survey, they may have been fearful that fellow students or their professor would see their answers, and therefore may not have answered honestly. Even though the questionnaires were completely anonymous, some of the students may have felt vulnerable to people seeing their responses and may have disregarded certain sensitive questions.

Other limitations to the study relate to sampling. The sample was drawn from an ethnically diverse university, yet the study did not specifically explore multicultural differences in attitudes and behaviors associated with condom use. Although ethnicity was included as a demographic variable, the analytical focus was on gender differences. 
Cultural beliefs and traditions about health behaviors vary greatly among different ethnic groups. Sensitivity to these multicultural differences is extremely important for using the findings to develop and implement reproductive health education programs.

Finally, there may be sampling bias because the study population was chosen from a university in the San Francisco Bay Area. Due to its location in an ADS epicenter, the San Francisco Bay Area has had many safer sex and condom campaigns over the past twelve years. As a result, the safer sex knowledge of these respondents may not be representative of college students in other parts of the country. Students living in this area, having been exposed to these campaigns, may be more aware of the risks of unsafe sex and have more favorable attitudes towards condom use.

\section{Significance of the Study}

Few studies have examined gender differences in condom use and safer sex behaviors among college students. The purpose of this study was to determine whether attitudes and behaviors associated with condom use differ between males and females, and to examine the factors related to any observed differences. The findings indicated that sexually active males used condoms more often over the past year than did females, and that males intended to use condoms in the future at a significantly higher rate than females. Compared to male respondents, females reported they had previously talked to a sexual partner about using condoms even though they reported low condom use. Awareness of these gender differences will assist college health educators in developing HIV/STD 
prevention programs, safer sex workshops, peer education activities, and pregnancy prevention materials that are sensitive to attitudes and behaviors of both men and women. Utilization of these findings can help increase the practice of healthy behaviors on college campuses and reduce the prevalence of HIV and STDs among our youth. 
Chapter 2

\section{LTTERATURE REVIEW}

\section{Theoretical Framework}

The theoretical framework for this study spans a range of disciplines and theories. Psycho-social, gender role, and health behavior theories were all incorporated to form the basis for this research. Each of these theories will be summarized and then specific research applications to condom use will be reviewed.

\section{Health Belief Model.}

For more than three decades, the Health Belief Model (HBM) has been one of the most influential and widely used psycho-social approaches to explaining health related behavior (Rosenstock, 1991). The Health Belief Model has three key components: (a) perceived susceptibility and seriousness of an illness, (b) perceived benefits of a certain action to prevent the illness and the barriers to taking that action, and (c) self-efficacy about carrying out the recommended behavior.

Several studies have used the Health Belief Model as the theoretical base for determining safer sex behavior with adolescents (DiClemente et al., 1992; Orr et al., 1992; Petosa \& Jackson, 1991) and college students (Manning, Balson, Barenberg, \& Mizell Moore, 1989; Radius et al., 1991). In their study of female adolescents, Orr et al. (1992) hypothesized that the likelihood of condom use is directly influenced by the reason for, or 
the perceived benefit of, condom use. The researchers developed a model which hypothesized the relationship between the HBM and condom use in preventing sexually transmitted diseases (STDs). This model hypothesized that condom use was influenced by (a) modifying and enabling factors, (b) specific attitudes and beliefs about condoms and STDs, and (c) the perceived threat and seriousness of STDs.

Their results showed that more than $50 \%$ of the sample reported some experience with condoms (Orr et al., 1992). Among the respondents who had reported using condoms, $11 \%$ said they always used condoms for protection against AIDS, $12 \%$ said they always used condoms for protection against STDs, and 20\% reported using condoms for protection against pregnancy. Respondents were allowed to report on more than one reason for using condoms. Of the sample of 390 sexually active adolescent females, only $22 \%$ reported using a condom the last time they had intercourse.

DiClemente et al. (1992) used the Health Belief Model as a theoretical framework in their study of condom use among junior high school students. Results identified four factors which were significantly associated with consistent condom use among their sample. Females, adolescents with low perceived barriers to condom use (such as condoms are uncomfortable to wear), adolescents who felt condoms were effective in preventing AIDS, and a lower number of lifetime sexual partners were all positively associated with condom use.

Petosa and Jackson (1991) tested the Health Belief Model concepts to predict adolescent intentions to adopt safer sex behaviors in an effort to reduce the risk of HIV. 
The variables they tested were (a) perceived susceptibility, (b) perceived severity, (c) cues to action, (d) perceived barriers, (e) knowledge of the disease, and (f) knowledge of preventive action. They found that the model was helpful in understanding the cohort of seventh and ninth graders but not eleventh graders. The older cohort had other forces working against safer sex behaviors, such as a need for acceptance, esteem, and affection.

One study (Manning et al., 1989) identified several reasons why college students did not feel susceptible to AIDS and the obstacles to practicing safer sex. The findings showed that there were misunderstandings about the transmission of AIDS and a condom's ability to protect against disease. Among the responses was the perception by the males that when females are on birth control pills a condom is not needed in a monogamous relationship. The authors emphasized the need for health educators to help college students differentiate between misunderstandings and facts about condoms.

\section{Social Learning Theory and Self-Efficacy.}

Social Learning Theory (SLT) states that when people lack a sense of self-efficacy, they do not manage situations effectively even though they know what to do and possess the requisite skills (Bandura, 1989). This theory addresses both the psycho-social dynamics underlying health behavior and the methods of promoting behavior change (Perry, Baranowski, \& Parcel, 1991). Environmental, behavioral, and personal factors interact to explain, and eventually change, human behavior according to SLT. 
One component of SLT is perceived self-efficacy. Self-efficacy is the confidence a person feels about performing a particular activity (Perry et al., 1991). Self-efficacy is an important prerequisite to behavior change because it provides an individual with confidence about his or her performance in a certain activity. Self-efficacy theory allows us to explore individuals' social skills, perceived benefits of performing a specific preventive act, and sense of control over a situation. The concept is especially important when exploring gender differences because of the self-confidence required to talk to a potential partner about using condoms (Bandura, 1989). Bandura's self-efficacy construct can be related to a person's perception of his or her ability to use a condom properly, which will in turn increase potential condom use. "Expectations of mastery affect both initiation and persistence of coping behavior" (Bandura, 1977, p. 193).

In one study with college students, Keller (1993) drew upon Social Learning Theory to determine why young adults do not protect themselves against sexual transmission of HIV. In a sample of 272 students, average age of 19 years, $72 \%$ reported having had sexual intercourse in the past. Of these sexually active students, $62 \%$ reported they had not used a condom even once during sexual intercourse.

The students were surveyed on their beliefs about transmission and preventive strategies in preventing sexual transmission of HIV. Results showed that the students' knowledge level was high; however, their feelings about condoms were negative. Many had experienced problems when using condoms: (a) condoms not having proper lubrication, (b) poorly fitting condoms, (c) condom breaking during intercourse, and (d) 
condom falling off during intercourse. The researcher used self-efficacy to relate the students' low condom use to their reported problems with condoms (Keller, 1993).

The self-efficacy model has been the theoretical base in several studies on reported and intended condom use among college students (Basen-Engquist, 1992; Brafford \& Beck, 1991; Brien et al., 1994; Goldman \& Harlow, 1993; Joffe \& Radius, 1993; O'Leary et al., 1992; Wulfert \& Wan, 1993). Bandura theorized that college students' low level of self-efficacy in using condoms contributes to their lack of condom use (Brafford \& Beck, 1991). Unlike protection against pregnancy, where women can exercise independent control, use of condoms requires them to exercise control over the behavior of men (Bandura, 1989).

Social Learning Theory was used in developing a measurement scale to test selfefficacy in condom use (Brafford \& Beck, 1991). This scale, appropriately named the Condom Use Self-Efficacy Scale (CUSES), has since been used by other researchers (Brien et al., 1994). The scale includes 15 factors which may influence college students' condom use behavior in response to the AIDS epidemic and includes several statements regarding self-efficacy. Brafford and Beck (1991) hypothesized that college students lacked necessary skills for safer sex practices such as the mechanics of using a condom and interpersonal communication with a potential sexual partner.

Brafford and Beck (1991) administered the CUSES to 768 college students. Their results showed low self-efficacy in the areas of purchasing condoms, discussing condom 
use with a potential partner, suggesting a new partner use a condom, and using a condom without any decreased sensation.

In keeping with the methodology of the CUSES, Brien et al. (1994) compared three distinct groups of college students. The researchers defined these groups as "nonusers," "sporadic users," and "ritualistic users" of condoms (p. 168). Identification with a group was determined by the participants' reported use of condoms over the past year. All of the participants in the study were sexually active. In their sample of 339 college students, results showed that $20 \%$ were nonusers, $51 \%$ were sporadic users, and $28 \%$ were ritualistic users.

The researchers found that the number of sexual partners, alcohol consumption, and self-efficacy were all important in predicting condom use. Nonusers lacked confidence in their abilities to discuss condoms and insist on condom use, and to negotiate and communicate with their partners about condoms. Ritualistic users were much more confident and able to communicate with their partners about condom use (Brien et al., 1994). Overall, the results showed a higher reported use of condoms among participants with greater self-efficacy and confidence (Brien et al., 1994). These findings were similar to those in which the CUSES had been administered to college students (Brafford \& Beck, 1991).

O'Leary et al. (1992) used Social Learning Theory as their theoretical base in a study of predictors of safer sex behaviors among college students. The key variables included (a) students' self efficacy to perform safer sex behaviors, (b) negative outcome 
expectancies regarding condom use, (c) perceived social norms, and (d) perceived potential risk of contracting HIV. They found that the negative expected outcomes of using condoms (such as using a condom would decrease sexual pleasure), along with students' self-efficacy to practice safer sex, were strong determinants of condom use. In Social Learning Theory (SLT), perceptions of self-efficacy to carry out desired behaviors successfully, as well as positive and negative outcome expectancies regarding safer sex behaviors, are the key determinants of effective behavior change (O'Leary et al., 1992). Joffe and Radius (1993) studied incoming college freshmen to determine if the students' perceived self-efficacy influenced their intent to use condoms at their next intercourse. Eight items on condom self-efficacy were incorporated into a general health survey administered to all incoming freshmen. The items included (a) communicating with a steady and potential partner about condoms; (b) ability to purchase, carry, and put on condoms; (c) enjoying sex with a condom; and (d) refusing sex with someone who will not use a condom.

Overall, their results showed that perceived self-efficacy plays a role in determining college students' intent to use condoms. Sexually active males and females scored higher than the never sexually active group in all areas except confidence in refusing sex with a new partner not wanting to use condoms. The researchers concluded that education and confidence building among young adults is of vital importance in teaching them to practice safer sex. 
Wulfert and Wan (1993) predicted that AIDS knowledge would not affect safer sex behavior in college students because Social Learning Theory does not view education as a sufficient cause of self-motivated behavior. They theorized that sexual attitudes, condom use expectancies, and peer group comparison would lead to self-efficacy in these students. This component, along with AIDS knowledge leading to perceived vulnerability, would theoretically lead to condom use among this cohort.

Quantitative research was conducted on all of the above variables. The researchers found that students' views about the effectiveness of condoms were positively correlated with use and self-efficacy, which is consistent with Social Learning Theory (Wulfert \& Wan, 1993). Reported use of condoms was low; almost $75 \%$ of the students responded with "never" or "sometimes" when asked about condom use during the previous six months. The main reasons for using condoms were for birth control and following their peers' attitudes about condoms. Finally, the only variable not associated with either self-efficacy or condom use was the respondents' attitudes about sex. The researchers stated the need to focus on self-efficacy beliefs in condom promotion and education programs.

Focusing on self-efficacy, control and meaning, and perceived risk, Goldman and Harlow (1993) hypothesized that these factors would be positively related to ADSpreventive behavior in college students. They further expected to find gender differences among the three constructs. Their results showed that the males and females studied 
engaged in risky sexual behavior, while believing that they were not putting themselves at risk for HIV.

In summary, many studies have successfully used psycho-social theories, including the Health Belief Model, Social Learning Theory, and self-efficacy in their framework. The present study used the Health Belief Model and Social Learning Theory as the conceptual framework for exploring attitudes and behaviors associated with condom use among college students.

\section{Gender Role Theories.}

Previous research on gender roles helps to understand gender differences in condom attitudes and behaviors. This research also was helpful in framing the present study and provided insight as to why gender differences may exist in sexual behavior. The literature on gender differences in social behavior suggests that these differences may carry over to the way males and females relate to condom use (Eagly \& Steffen, 1984).

Oliver and Hyde (1993) performed a meta-analysis of the research literature on gender differences in sexuality. The theories included in the meta-analysis were (a) neoanalytic, (b) sociobiology, (c) Social Learning, (d) social role, and (e) script.

One neoanalytic theorist, Chodorow, postulated that the cause of gender differences was rooted in early family experiences of boys and girls. According to this theory, boys and girls experience their mothers as the primary caregiver and are, therefore, emotionally attached to her. Girls remain attached while boys find the need to look for a 
distinct masculinity. Chodorow explains that masculinity involves denying feminine maternal attachment (cited in Oliver \& Hyde, 1993). This theory concludes that women are attracted to men as erotic objects, but find emotional attachment necessary to engage in sex with a man they are attracted to.

Sociobiologists address society's double standard of permissive attitudes towards male promiscuity but intolerance of female promiscuity. They point out that men's sperm are plentiful while women's eggs are less plentiful and considered precious. From this perspective, it makes "evolutionary sense" for men to inseminate many women with their sperm, but women need to be particular about who will inseminate them. Sociobiologists also contend that a woman must commit nine months of her life to gestation and as a result, has that much more time invested in the child than does the father. This theory, developed mainly by Donald Symons, concludes that men should be more approving of casual sex, and women should not (cited in Oliver \& Hyde, 1993).

One application of Social Learning Theory by Mischel in 1966 (cited in Oliver \& Hyde, 1993) helps to explain gender differences in sexual behavior. From this theoretical perspective, gender differences and other behaviors are formed by positive reinforcement (Bandura, 1989). Children typically imitate same-gender adults. Parents, the media, and other sources are models for imitation for developing children. Social Learning Theory predicts that patterns of gender differences change over time, and as long as a sexual double standard for men and women is apparent in society gender differences can be expected (cited in Oliver \& Hyde, 1993). 
Social role theory is based on the effect gender roles have on gender differences and the part that society's double standard plays in sexuality. American society's sexual Jouble standard has changed over the years and has evolved into more acceptance of sex outside of marriage for both sexes, but less tolerance for a female's sexuality unless she is in love or engaged. Social role theory is able to predict change over time in gender differences regarding sexuality as broader gender roles change (cited in Oliver \& Hyde, 1993).

In addition to gender roles affecting sexual behaviors, scripts also play a part. Scripts are the interpersonal or internal roles males and females follow when engaged in mutual sexual interaction. Script theory maintains that gender differences begin in early adolescence. This is a time when boys are experiencing their sexuality through masturbation and girls are focusing more on becoming adult females, according to the theory. Girls begin to have sexual experiences much later than boys, and when they do, it is usuaily in a heterosexual relationship. Script theory emphasizes, according to Gagnon and Simon (cited in Oliver \& Hyde, 1993), that sexuality is tied to individual pleasures for males and quality of relationships for females.

In summary, these distinct theories have been designed to address gender differences in sexuality. The common thread in all of them is that women will have fewer partners than men and will have more negative attitudes towards casual and premarital sex. This research serves as a base for understanding the differences found in this study. 


\section{$\underline{\text { Condom Use Studies }}$}

Gender-specific condom use behavior has been studied in many ways. Examples include single sex research with females (Valdiserri, Arena, Proctor, \& Bonati, 1989; Wilson, Jaccard, Endias, \& Minkoff, 1993) or males (Tanfer, Grady, Klepinger, \& Billy, 1993), by hypothesizing gender differences in condom use (Carroll, 1991; Goldman \& Harlow, 1993), and by analyzing results gender-specifically (Brien et al., 1994; Petosa \& Jackson, 1991).

Many of the studies outlined here used samples of undergraduate students (ages 18-24) while others were done with adolescents (ages 13-19). In many cases, the age groups overlap between the adolescent subjects and college students. Because the current study focused on undergraduate students, it was useful to review the vast literature on adolescents' attitudes about condoms.

\section{Studies of Females.}

Several studies indicate that young women do not rely on condoms for disease protection as often as young men (Catania, 1989; Collins et al., 1993). In this era of AIDS, the educational focus on safer sex behaviors has been primarily on males (Holmes \& Fernandez, 1988), and may explain why women do not rely on condoms for disease protection.

Wilson et al. (1993) point out that males have traditionally had the responsibility of carrying and knowing how to use condoms, while females have been uncomfortable with 
the idea of carrying condoms. Females, therefore, may lack accurate information regarding condoms and may feel inadequate at being responsible for their use. The purpose of their study was to determine whether attitudes towards carrying condoms were derived from attitudes about condoms specifically, or the beliefs around carrying condoms. They hypothesized that if a woman felt negatively about condoms, she would be opposed to carrying them.

Wilson et al. (1993) used value-expectancy theory as the framework for their study. According to this theory, "an individual's attitude is a psychological summary of the set of beliefs that individual has about the advantages and disadvantages or perceived consequences of performing that behavior" (Wilson et al., 1993, p. 1095). They surveyed 971 heterosexual women in the New York City area. They assessed the women's attitudes towards using and carrying condoms, beliefs about carrying condoms, and sexual risk behavior. They found that the most significant barrier to carrying condoms was the social stigma placed on women if they carried condoms. The researchers concluded that there is a need for increasing the media's portrayal of positive images associated with women carrying condoms.

Rickert, Jay, Gottlieb, and Bridges (1989) recruited adolescent females (12-19 years old) from a teen clinic and assessed their feelings about purchasing and using condoms. In their sample of 99 females, $85 \%$ reported sexual activity at a median age of 13 years old. Slightly less than three quarters of the sample were knowledgeable about a condom's effectiveness in preventing disease, but only $10 \%$ reported having used a 
condom in the past. Of those who had reported condom use, only $17 \%$ had bought condoms themselves. The researchers suggested that younger females may be more embarrassed to talk to their partners about condoms and, therefore, may be at greater risk for sexually transmitted diseases (Rickert et al., 1989).

Valdiserri et al. (1989) surveyed 759 women, 19-25 years old, about their behaviors and attitudes towards condoms. Fully $82 \%$ reported they had used condoms at least once, but only $21 \%$ reported that they were currently using condoms. The study population appeared to lack accurate information about the proper use of condoms and the protection a condom offers against AIDS. More than one quarter of the women believed that petroleum jelly (e.g., Vaseline) was the best lubricant to use with condoms, $21 \%$ believed withdrawal of the penis before ejaculation is just as safe as using a condom in preventing AIDS, and nine percent believed that a woman could not get AIDS from a man unless she had anal intercourse with him; all of which are incorrect.

When questioned about their attitudes regarding condoms, $80 \%$ of the young women believed that men do not like using condoms, even though $87 \%$ felt they would ask a potential partner to use condoms if they had sex. The authors recommend condom promotion programs that include skills building, role playing, and small group discussion (Valdiserri et al., 1989). Their findings were similar to previous research on predictors of condom use among adolescent females with more than one sex partner (Catania, 1989; Radius et al., 1991). 
Catania (1989) hypothesized that condom use among females was associated with several factors: (a) her number of sexual partners, (b) her communication skills, (c) social norms, (d) her perceived vulnerability to AIDS, (e) self-efficacy, and (f) her attitudes towards sex. The study population consisted of 114 young women (12-18 years old) who were surveyed in family planning clinics. Results showed that $96 \%$ had experienced vaginal intercourse, but condoms were only used an average of $27 \%$ of the time. Greater enjoyment of condoms and a greater willingness to request that partners use condoms were found to be predictors of condom use behavior.

Radius et al. (1991) found that female college students who used oral contraceptives $(\mathrm{OC})$ put themselves at higher risk for STDs and AIDS than females who used barrier methods of contraception, such as condoms or diaphragms. The OC users reported having more sexual partners than the females using barrier methods, were more likely to have sex after drinking alcohol, and felt they put themselves at high risk for STDs. The results also showed that the females who used barrier methods expressed more concern about getting AIDS than the other group. The researchers emphasized the need for reproductive health educators to focus education efforts on disease prevention as well as pregnancy prevention.

In a study comparing three cohorts of college females, DeBuono et al. (1990) found that although females were using condoms on a more regular basis, they still did not use them a majority of the time. This comparative study was done by surveying the sexual practice of college females in 1975,1986 , and 1989. The subjects were clients of a 
gynecological clinic on a college campus and were invited to participate during clinic visits.

The results found no significant differences between the three groups regarding their reported sexual behaviors, the reported frequency of condom use among the three groups of females, or the number of sexual partners over the past year. When asked about frequency of condom use, $12 \%$ of the 1975 cohort, $21 \%$ of the 1986 cohort, and $41 \%$ of the 1989 cohort reported "always or almost always" using condoms during sexual intercourse. Even though this increase is significant, and appears to show that females are becoming more aware of the benefits of using condoms, more than half of the 1989 cohort reported "seldom or never" using a condom. The authors recommended more condom education for females (DeBuono et al., 1990).

\section{Studies of Males.}

Tanfer et al. (1993) hypothesized that socioeconomic status, age, race, social norms, and knowledge of HIV/STDs would all be predictors of condom use among men. In their study of 2,608 men, aged 20-39 years old, they found that age and marital status were the most significant predictors of condom use. This sample may not reflect the college population age group behavior; however, the results are relevant. Men aged less than 30 , the traditional college age population, were twice as likely to report condom use than men age 30 and older. Thirty nine percent of single men reported condom use compared with only $18 \%$ of married men. Ethnicity also played a significant role, with 
$38 \%$ of African American men reporting condom use compared to $25 \%$ of white men. Overall, Hispanic men reported higher condom use than non-Hispanic men, which is not consistent with other research in this area (Collins et al., 1993; Hodges et al., 1992).

Among the reasons for condom use within this study population were birth control only (49\%), but $43 \%$ indicated that they used condoms for birth control and disease prevention. For men under age 30, half reported using condoms for birth control and disease prevention. Among the single men studied, $63 \%$ said they used condoms for both disease prevention and birth control.

Self-efficacy was not considered in this study; however, belief in a condom's efficacy in preventing pregnancy "much better" than another method was found in $32 \%$ of the men. Overall, only $27 \%$ of the participants reported using a condom at least once during the previous four weeks. The researchers attributed this to the larger percentage of married men in the sample. However, even single men reported low use of condoms. The researchers concluded that there is a need to increase condom education programs for men (Tanfer et al., 1993).

\section{Male and Female Studies}

Leland and Barth (1992) did not find a difference between male and female adolescents' overall use of condoms. However, they noted that males reported a higher use of condoms (84\%) at last intercourse compared to females $(64 \%)$. When questioned about STD prevention, there were significant differences between genders. Males were 
more aware than females that latex condoms were better than animal skin condoms in preventing disease transmission, and that condoms protect against disease better than contraceptive sponges. Females reported having sex more often and were less likely than males to know the correct way to use condoms.

Females were more likely than males to discuss birth control with their parents, which the researchers point out may be due to the responsibility placed on a female in the event of an unintended pregnancy. Still, the females in this study reported inconsistent use of birth control because they were uncomfortable obtaining it, more likely to rely on withdrawal as a birth control method, and less likely to have used birth control during their first intercourse. The researchers emphasize the need to stress both pregnancy and disease prevention methods in reproductive health education curricula for females (Leland \& Barth, 1992).

Goldman and Harlow (1993) hypothesized that there would be gender differences in condom use behavior among college students based on self-efficacy, control and meaning, and perceived risk. They found that men scored significantly higher among AIDS-perceived risk measures and women scored significantly higher on measures of AIDS efficacy and preventive behaviors. The researchers concluded that even though females have more knowledge of the effectiveness of a condom against HIV, they are not the ones in control of the act of using a condom and, therefore, must convince male partners to wear one. If males do not perceive condoms to be effective against HIV, they will not wear one, putting both partners at risk. The researchers predicted that females 
who have the ability to convince their partners to wear condoms will report less susceptibility to HIV (Goldman \& Harlow, 1993).

Sacco, Rickman, Thompson, Levine, and Reed (1993) found that college-aged males and females did not differ in their reported past or intended use of condoms. For both genders, the rate of past condom use was between $25-40 \%$ of the time. They did find that females reported they were less likely to (a) carry condoms or keep condoms at home and (b) intend to carry or keep condoms at home. These findings suggest that females expect their male partners to carry condoms and take responsibility for their use. Females yielded an average response of between "never" and "rarely" in the category "intending to carry condoms."

Attitudes in relation to condom use were similar between males and females. Sexual self-control (e.g., wearing a condom even in the heat of passion) as a predictor variable, was consistently the highest for both genders. Two common reasons for selfcontrol were relationship safety and a condom's effect on sexual pleasure. Males also identified interpersonal relationship as a predictor for self-control. Females were less likely than males to view people who carried condoms as promiscuous. Sacco et al. (1993) hypothesized that these gender differences are due to gender roles.

Baldwin and Baldwin (1988), in their study of college students in Southern California, found several significant predictors of condom use. Their sample of 513 students consisted of heterosexual, non-married males and females who had engaged in vaginal intercourse within the previous three months of the study. Two-thirds of the 
sample $(66 \%)$ reported never having used a condom within this time frame. Condom use was significantly higher among students from households with higher paternal education and parental income, those who waited until later in life to become sexually active, and those reporting seat belt use. Hispanics reported the highest rate of condom use among all ethnic groups.

The only significant gender difference in their study was that females indicated taking fewer sexual risks, and therefore had less casual sex than males. The researchers attributed this to the fact that females take more precautions than males because they endure more significant risks from unprotected sex, such as unplanned pregnancies. They recommend that males be educated in this area and learn to take precautions to prevent these situations (Baldwin \& Baldwin, 1988).

Carroll's (1991) research on college students addressed three core areas: (a) would college students who were more knowledgeable about AIDS report practicing safer sex more often than lesser educated students, (b) would students who reported behavior change report practicing safer sex, and (c) would gender have an effect on these behaviors. He surveyed 592 undergraduate, sexually active college students about their condom use and frequency of sexual intercourse over the past year. Results showed that there were no significant differences between gender in their reported use of condoms. Males who were more knowledgeable about AIDS reported being more selective with sexual partners than females and tended to have sex less frequently than females. Carroll 
(1991) hypothesized, from these results, that college-aged females feel less vulnerable to AIDS and may have lower self-efficacy and control over condom use than males.

Hawkins et al. (1993), in a similar study with college students, found that females were more selective with their sexual partners and had reduced their number of sex partners as a safer sex practice. This finding was not associated with the students' knowledge about AIDS. Even though these students reported awareness of safer sex practices, overall only $24 \%$ reported using condoms. Reported condom use was $27 \%$ among females and $29 \%$ among males.

Burger and Inderblitzen (1985) tested college students' contraceptive behavior and examined the roles of communication, knowledge, self-esteem, and sexual anxiety. They surveyed 52 male and 71 female undergraduate students in the above four areas. For males, general communication comfort level was positively associated with contraceptive behaviors. For females, sexual communication with a partner indicated contraceptive behavior. A lack of communication between partners increased the possibility that males and females would assume their partner is taking the responsibility of contraception. Selfesteem appeared to be a poor predictor of contraceptive behavior. Overall, there were no significant gender differences in this sample (Burger \& Inderblitzen, 1985).

In a large Canadian study $(\underline{\mathrm{N}}=5,574)$, MacDonald et al. (1990) found that college students' reported condom use was low. Results showed that $74 \%$ of the males and $69 \%$ of the females reported having sexual intercourse at least once. Males reported "always" using condoms $25 \%$ of the time compared to just $16 \%$ for females. As the number of 
sexual partners increased for females, their use of condoms decreased significantly, and oral contraceptive use increased. Females also reported, significantly more often than males, that the embarrassment of buying condoms was a factor negatively influencing condom use. The researchers emphasized the need for behavior-focused educational programs to improve condom use and reduce STD/HIV risk (MacDonald et al., 1990). In his study with college students, Yesmont (1992) examined assertive and aggressive behaviors in response to talking to partners about safer sex and explored gender differences in communication. Yesmont studied single, heterosexual, sexually active college students. Results showed that there was no significant difference between males and females in condom use over the previous year. Using a response scale from 0 $100 \%$, nonassertiveness was associated with $0 \%$ condom use, and $100 \%$ condom use was associated with a higher safer sex assertiveness in communication. Overall, males were less assertive than females in communicating safer sex. Yesmont emphasized the importance of self-perceived effective communication in safer sex behaviors.

Turner et al. (1993) hypothesized that college students would reduce sexual risk behaviors following a comprehensive health education intervention. In their case-control study, they compared the sexual risk behaviors of 341 students who had received a health education seminar their first semester of school to the behaviors of 227 students who were not enrolled in the seminar. Condom use increased for both males and females. However, males reported a significant increase in abstinence immediately after completing the health education seminar. These results show the effectiveness of a comprehensive health 
education program on the safer sex practices of college students and suggest the presence of other safer sex learning opportunities in the college environment.

In summary, there is a rich body of research in the area of safer sex behaviors among college students, adolescents, males, and females. Much of this research is theorybased, utilizing the Health Belief Model, Social Learning Theory, and self-efficacy theory. Few studies have focused specifically on gender differences and safer sex behavior, but those that have found interesting and important differences. Among the salient gender differences are (a) a greater reported use of condoms by males, (b) females' embarrassment about carrying or purchasing condoms, (c) difficulty for males in communicating with a female partner about safer sex and condoms, and (d) the reason for using condoms (i.e., disease protection or pregnancy prevention).

The research suggests that females do not use condoms when they are on birth control pills or when they lack accurate information regarding correct use. Males tend to use condoms when they are more knowledgeable about condoms. Predictors of condom use by males are age, race, and marital status.

Research on gender role theory gives insight into how contemporary American society views sexuality and answers several questions about how males and females cope with sexuality issues. Prior research in the area of gender roles indicates that gender differences are formed by society's sexual double standard. The roles that society places upon young males and females develop into gender differences in adulthood. Genderfocused research indicates that these differences influence sexual attitudes and behaviors. 
The literature reveals the need for further research into gender differences, particularly among young people, to determine the reasons behind an inconsistent use of condoms. Research focused specifically on the predictors of condom use, safer sex behaviors, and sexuality issues of college males and females is essential. 


\section{Chapter 3}

\section{METHODOLOGY}

\section{Overall Research Questions}

This research was designed to address the following research questions:

1. Is there a difference in the self-reported use of condoms between sexually active young males and sexually active young females?

2. If a difference in condom use exists, what factors are associated with this difference?

3. Are there differences in attitudes, self-efficacy, or health beliefs between males and females regarding condom use?

\section{Objectives}

This research was designed to meet the following objectives:

1. To determine if there is a gender difference in the use of condoms among undergraduate sexually active males and females.

2. To generate data useful for reproductive health educators in designing more effective educational programs and materials.

3. To add to the emerging literature on college health, safer sex behaviors, and gender-relevant safer sex education for young people. 


\section{Conceptual Definitions}

The following conceptual definitions were used in designing the study:

College Students: $\quad$ This term was used interchangeably with "young people" to describe both the subjects invited to complete questionnaires in this study and the broader population they represent. College students were assumed to be between 18 and 40 years old and enrolled in undergraduate courses.

Sexually Active: $\quad$ This term refers to an individual who has, sometime in their life, engaged in vaginal or anal intercourse.

Safer Sex: This term refers to anal, oral, or vaginal intercourse in which a method of disease and/or pregnancy prevention, such as a condom, is used.

Self-Efficacy: $\quad$ Self-efficacy is the confidence a person feels about performing a particular activity (Perry et al., 1991). Selfefficacy theory allows us to explore an individual's social skills, perceived benefits of performing a specific preventive act, and sense of control over a situation (Bandura, 1977). 
Health Belief Model: The Health Belief Model (HBM) is composed of three key components: (a) perceived susceptibility and seriousness of an illness, (b) perceived benefits of a certain action to prevent the illness and the barriers to taking that action, and (c) self-efficacy about carrying out the recommended behavior in preventing illness (Rosenstock, 1991). The HBM was designed to study health behaviors.

Gender: $\quad$ Male or female.

\section{Operational Definitions}

The following operational definitions were used for the purpose of this study:

College Students: The participants in this study were sexually active undergraduate students enrolled in Health Science and Engineering courses on the campus of San Jose State University, San Jose, California. College students participating in this study were between the ages of 18 and 40 , self-identified as students, and included both males and females. 
Sexually Active: Question \#21 of the questionnaire asked whether or not the respondent had ever had sexual intercourse. Any participant who answered "yes" to this question was considered to be sexually active. It was not necessary in this research to determine if a participant was currently sexually active.

Condom Use: $\quad$ In this research, it was necessary only to determine if condoms had ever been used by a participant. A response of "yes," to the question regarding use of a condom in the past (\#22), or a response other than "never" to the question about the frequency of condom use over the past year (\#26) determined if the participant used condoms.

Regular Use: $\quad$ A response of "more than half the time" to the question regarding the frequency of condom use over the past year (\#26), or a response of "yes" to the question asking if the participant planned to use condoms the next time $(\# 27)$ determined regular use of condoms. 
Safer Sex:

Self-Efficacy:

Health Beliefs:
For the purpose of this study, safer sex was defined as the use of some form of pregnancy protection or STD protection during sexual intercourse. Examples include condoms, contraceptive foams or jellies, female condoms, or other forms of birth control indicated in question \#31.

In this research, self-efficacy was defined as the participant's expectation of using condoms properly and having the confidence to talk about and use condoms. Low selfefficacy was determined by an "agree" or "strongly agree" response to the following Condom Knowledge and Attitudes questions: (a) condoms are too embarrassing to buy (\#15), (b) condoms are difficult for me to use (\#17), and (c) condoms are embarrassing to talk about (\#19).

Health beliefs refer to a participant's belief about the protection and reliability a condom provides in preventing pregnancy, STDs, and HIV. Health beliefs about a condom's efficacy were determined by the responses to (a) condoms protect me from getting AIDS or other sexually 
transmitted diseases (\#14), and (b) condoms do not protect me from getting a disease (\#20).

Monogamous: $\quad$ Self-identification of being monogamous was indicated by a participant's response to the question regarding relationship status (\#9).

Gender: $\quad$ A participant's gender was determined by their response to the question asking if they are male or female (\#2).

\section{$\underline{\text { Research Design }}$}

This study used a cross-sectional research design to collect descriptive data concerning college students' attitudes and behaviors regarding condom use. Data collection was done through an anonymous survey of San Jose State University undergraduate students.

\section{Questionnaire}

The original survey questionnaire, designed by the researcher, contained nine demographic questions, eight Likert-type scale questions regarding attitudes and knowledge about condoms, 12 questions pertaining to the participants' sexual activity, and three questions addressing the effectiveness of condoms in preventing disease transmission 
and pregnancy (see Appendix A). The participants were also asked about previous safer sex or condom education they had received.

A focus group of six college students participated in a pilot study. The purpose of the pilot study was to review the questionnaire and determine if it was clear, attractive, seli-explanatory, and used language appropriate for the study population. The pilot study results revealed a need for several minor revisions. A reorganization of question layout, the addition of open-ended questions, and several wording changes were incorporated into the final questionnaire.

Subjects

Subjects were recruited from undergraduate Health Science and Engineering classes at San Jose State University. The sampling goal was 250 undergraduate students. Health Science and Engineering classes were chosen in order to recruit a group of students with varied experiences with AIDS, STDs, and contraceptive education. Professors teaching Health Science and Engineering courses were contacted by phone, told about the research, and asked if they would be willing to allocate 15-20 minutes of class time for data collection. Data collection was scheduled with the professor at a time most convenient for the class. Only classes with prior professor consent were sampled. Approval from the San Jose State University Human Subjects-Institutional Review Board was obtained before recruiting subjects and collecting data (see Appendix B). 
Informed consent was emphasized to all potential participants. The researcher explained that participation was completely voluntary and that non-participation would not affect the students' relationship with their professor or the University in any way. The researcher explained the purpose of the research and each participant was given an informed participation form, previously signed by the researcher, with the study details outlined (see Appendix C). Participants were asked to sign the informed participation form and keep it for their records. Following explanation of the research, questionnaires were distributed to participants in each classroom with the professor present.

Participants were given as much time as was needed to complete the questionnaires. Students placed completed questionnaires face down on a table in the front of the room. All returned questionnaires were placed in an envelope which was then sealed. As an incentive, students returning a completed questionnaire were invited to take free condoms. The condoms were purchased at the University's Health Services Condom Co-op and all participants received information about the service. Participants were given the opportunity to receive study results by providing the researcher with their names and addresses on a postcard. Postcards and questionnaires were collected separately so that any possibility of associating the names with their respective questionnaires was eliminated. The students' names did not appear anywhere on the questionnaire and completed questionnaires were kept in a locked file cabinet in the researcher's home office. 
Analysis

All quantitative questionnaire responses were assigned codes prior to distribution of the survey. A comprehensive codebook was developed for data entry and analysis purposes (see Appendix D). Questionnaires were reviewed for readability, coded according to the codebook for all responses and blank answers, and sorted by the class where data was collected. Data was entered and analyzed by using the Epi Info, Version 5 statistics program for epidemiology on microcomputers (Dean, Dean, Burton, \& Dicker, 1990). All data was entered twice by the researcher and one research assistant and then checked for accuracy using a validation function in Epi Info.

Preliminary analysis was performed on all questionnaires to determine if students were graduates or undergraduates, married or single, and if they previously had engaged in sexual intercourse. Final analysis was performed only on those surveys received from sexually active, single, undergraduate students in keeping with previous research in this area. All other respondents were excluded from the final sample. Descriptive statistics were calculated to determine (a) male-to-female ratio, (b) the mean age of the sample, and (c) the distribution of Health Science and non-Health Science majors.

The independent, or predictor, variable in this study was gender. Gender was used to predict the outcome, or dependent variables: (a) previous condom use, (b) condom use at next intercourse, (c) intercourse with a potential partner without a condom, and (d) condom use over the past year. Specifically, analysis was performed to determine gender differences in predicting condom use behavior. 
Pairwise comparisons were performed on age to determine if age had a confounding effect on the relationship between condom use and gender. If a confounding effect was found, age-adjusted analysis was performed. Chi-square $\left(\chi^{2}\right)$ analysis was performed and Yates corrected $p$-value was used to determine if there were statistically significant gender differences relating to condom use behavior. Fisher's exact test was used if any of the expected values were less than five. If the $p$-value was less than .05 , it was considered statistically significant (Rosner, 1990). Chi-square analysis was performed on all independent variables. If analysis revealed trends among variables, a $\chi^{2}$ test for trends was performed. Frequencies were performed on all condom attitude and knowledge variables. Any gender differences were further analyzed using the KruskalWallis test for medians.

The questionnaire allowed participants to write comments in response to several open-ended questions (see Appendix A). All comments were read and categorized by theme. When statistically significant gender differences were identified for specific variables, the open-ended comments were examined in greater depth for insight into the differences.

\section{Methodological Assumptions}

The research design, particularly questionnaire development and sampling strategy, was based on several key assumptions. The researcher assumed that the survey questions would be clearly understood by all participants since it was being administered among 
university students. The participants' previous knowledge of what condoms are, the definition of safer sex, knowledge of various birth control methods, and the understanding of the terms "monogamous," "AIDS," and "sexual intercourse" were assumed by the researcher. It was assumed that the majority of students in the Health Science undergiaduate classes would be Health Science majors. It was further assumed that Health Science students, whether majors or not, would be more knowledgeable about safer sex because of the content of courses in their academic program.

The pilot study was designed to ensure that the language was appropriate for college students. It was assumed that all participants would be able to read and understand English at the level to which the questionnaire was written. Assuming there would be some variation in English skills, every effort was made to keep the wording simple and straightforward.

Compliance by the participants with data collection procedures was another assumption. The questionnaire was kept short and concise and it was assumed that participants would complete the entire questionnaire. All recruited participants were told that completion of the questionnaire was voluntary and a choice not to participate would not affect their reputation in the class or at San Jose State University. However, completion of the entire questionnaire by consenting participants was assumed.

A greater representation of Health Science than Engineering students in the final sample was assumed by the researcher. It was assumed that since the researcher was a graduate student in the Health Science Department at San Jose State University, it would 
be easier to recruit professors who were willing to allow data collection in their classrooms.

Finally, it was assumed that undergraduate Health Science and Engineering professors would be willing to allow the researcher into their classrooms, using class time, to distribute, explain, and collect the questionnaire. In addition to distributing the questionnaire, it was assumed that the professors would be willing to have the researcher distribute free condoms to all participants upon their return of completed questionnaires, and that students would not be offended by the opportunity to pick up a free condom. 


\section{Chapter 4}

\section{RESULTS}

\section{$\underline{\text { Sample }}$}

Seven Health Science and two Engineering professors were contacted by the researcher requesting permission to distribute questionnaires in their classrooms. The contacts were made during the Fall 1993 and Spring 1994 semesters at San Jose State University. Permission for data collection was granted from five Health Science professors and one Engineering professor. A total of 246 questionnaires were distributed and returned from eight classes.

A total of 81 students (33\%) who reported never having had sexual intercourse, were married or divorced, or who were graduate students were excluded from the study. Incomplete questionnaires were also excluded, producing a final sample size of 165 students. The final sample consisted of $93(56 \%)$ females and $72(43 \%)$ males with $72 \%$ of the students between the ages of 15 and 24 .

\section{Descriptive Characteristics}

Table 1 shows descriptive characteristics of the final sample for age group, major, relationship status, and ethnicity by gender. No significant age difference was found between males and females. However, a higher percentage of females $(72 \%)$ were 
between the ages of $15-24$ than males $(65 \%)$. A higher percentage of males $(29 \%)$ were between the ages of $25-29$ than females (17\%).

Table 1

Characteristics of Final Sample

\begin{tabular}{|c|c|c|c|}
\hline \multirow[b]{2}{*}{ Characteristic } & \multirow[b]{2}{*}{$\underline{\mathbf{n}}$} & \multicolumn{2}{|c|}{ Gender } \\
\hline & & $\%$ Females & $\%$ Males \\
\hline \multicolumn{4}{|l|}{ Age group } \\
\hline $15-24$ & 114 & 72 & 65 \\
\hline $25-29$ & 37 & 17 & 29 \\
\hline $30+$ & 14 & 11 & 6 \\
\hline \multicolumn{4}{|l|}{ Major } \\
\hline Health Science * & 55 & 46 & 17 \\
\hline Not Health Science & 110 & 54 & 83 \\
\hline \multicolumn{4}{|l|}{ Relationship status } \\
\hline Single & 102 & 54 & 72 \\
\hline Monogamous * & 63 & 46 & 28 \\
\hline \multicolumn{4}{|l|}{ Ethnicity } \\
\hline African American & 7 & 3 & 6 \\
\hline Asian/Pacific Islander & 49 & 28 & 32 \\
\hline White & 78 & 57 & 36 \\
\hline Hispanic/Latino & 18 & 8 & 15 \\
\hline
\end{tabular}

${ }^{*} \mathrm{p}<.05$ 
There was a significant difference between males and females with respect to major. A total of $46 \%$ of the females and only $17 \%$ of the males were Health Science majors $(p=.00013)$.

There was no significant difference between males and females and their sexual orientation. Most (94\%) of the sample identified with being heterosexual, 3.7\% reported they were either bisexual or homosexual, and $2.8 \%$ reported that they did not know their sexual identity. Two respondents (.01\%) did not answer this question.

A statistically significant difference $(\mathrm{p}=.024)$ was found between males and females in relationship status. Females were significantly more likely than males to say they were in monogamous relationships (see Table 1).

There was a marginally significant difference between males and females within ethnic groups $(\mathrm{p}=.05)$. A majority of females were white $(59 \%)$ while most of the males were evenly distributed between white (41\%) and African American and Asian/Pacific Islander (42\%). A total of 13 of the respondents (.08\%) did not respond to this question (see Table 1).

\section{Condom Knowledge and Attitudes}

Condom knowledge and attitudes about condoms were covered in questions $10-20$ on the questionnaire (see Appendix A). Table 2 shows the responses for these variables for males and females. There was a statisticaliy significant gender difference for the 
statement "condoms are difficult for me to use." Females (21\%) were more likely than males $(8 \%)$ to find this question not applicable $(p=.008)$.

Table 2

Condom Knowledge and Attitude Responses by Gender

\begin{tabular}{|c|c|c|c|c|c|c|c|}
\hline \multirow[b]{3}{*}{ Variable } & \multirow[b]{3}{*}{$\underline{\mathbf{n}}$} & \multicolumn{6}{|c|}{ Gender } \\
\hline & & \multicolumn{3}{|c|}{$\%$ Females } & \multicolumn{3}{|c|}{$\%$ Males } \\
\hline & & A & $\mathrm{D}$ & N/A & $\bar{A}$ & $\mathrm{D}$ & N/A \\
\hline Condoms accepted and used by people my age. & 165 & 84 & 13 & 3 & 85 & 15 & 0 \\
\hline Easy to have sex on the spur of the moment. * & 165 & 46 & 44 & 10 & 28 & 61 & 11 \\
\hline Condoms can be used without a prescription. & 165 & 96 & 1 & 3 & 96 & 1 & 3 \\
\hline I enjoy sex because I'm protected with a condom. & 165 & 65 & 18 & 17 & 57 & 31 & 13 \\
\hline Condoms protect from AIDS/STDs. & 165 & 94 & 4 & 2 & 88 & 8 & 4 \\
\hline Too embarrassing to buy condoms. & 165 & 25 & 67 & 9 & 25 & 68 & 7 \\
\hline Condoms decrease my sexual pleasure. * & 164 & 37 & 44 & 18 & 51 & 35 & 14 \\
\hline Condoms are difficult for me to use. * & 162 & 6 & 73 & 21 & 21 & 71 & 8 \\
\hline Condoms are the best form of birth control. & 164 & 32 & 63 & 5 & 44 & 43 & 13 \\
\hline Embarrassing to talk about condoms. & 165 & 13 & 82 & 5 & 21 & 74 & 6 \\
\hline Condoms do not protect against disease. & 165 & 12 & 84 & 4 & 14 & 78 & 8 \\
\hline
\end{tabular}


A Kruskal-Wallis test of medians showed that females responded significantly more favorably than males in response to the statement "condoms make it easier to have sex on the spur of the moment" $(p=.03)$. Similarly, females $(37 \%)$ were less likely than males $(51 \%)$ to agree with the statement "condoms decrease my sexual pleasure." This gender difference was also statistically significant using a Kruskal-Wallis test of medians $(\underline{p}=.02)$.

Two questions were asked regarding the disease protection of a condom. Nearly all of the females (94\%) and $88 \%$ of the males agreed with the statement "condoms protect me from getting AIDS and other sexually transmitted diseases." Similarly, $84 \%$ of females and $78 \%$ of males disagreed with the statement "condoms do not protect me from getting a disease."

\section{Age of First Sexual Experience}

Males and females responded quite similarly to the question "how old were you the first time you had sexual intercourse?". Fourteen percent of the sample reported that they were under 15 years old at first intercourse. More than half $(65 \%)$ reported that they were between 15 and 19 years old. No significant differences between males and females were found within the four age groups (see Table 3).

Table 4 illustrates the students' reported age of first condom use. More than half of the males $(69 \%)$ and females $(61 \%)$ reported first use between 15 and 19 years old. Thirteen $(.08 \%)$ of the respondents did not answer this question because they had not 
previously used a condom. There were no statistically significant differences between males and females within age groups.

Table 3

Age of First Sexual Experience by Gender

\begin{tabular}{lccc}
\hline & & \multicolumn{3}{c}{ Gender } \\
\cline { 3 - 4 } Age group $^{\mathrm{a}}$ & $\underline{\mathrm{n}}$ & \% Males & \% Females \\
\hline$<15$ & 23 & 15 & 13 \\
$15-19$ & 107 & 65 & 65 \\
$20-24$ & 34 & 19 & 23 \\
$25-29$ & 1 & 1 & 0 \\
\hline
\end{tabular}

Note. Values are in rounded percentages and may not equal $100 \%$.

${ }^{\mathrm{a}}$ No responses were given within age groups above 25-29 years old.

Table 4

Age of Initial Condom Use by Gender

\begin{tabular}{|c|c|c|c|}
\hline \multirow[b]{2}{*}{ Age group } & \multirow[b]{2}{*}{$\underline{n}^{a}$} & \multicolumn{2}{|c|}{ Gender } \\
\hline & & $\%$ Males & $\%$ Females \\
\hline$<15$ & 6 & 3 & 4 \\
\hline $15-19$ & 106 & 69 & 61 \\
\hline $20-24$ & 38 & 17 & 28 \\
\hline $25+$ & 2 & 1 & 1 \\
\hline
\end{tabular}

Note. Values are in rounded percentages and may not equal $100 \%$.

${ }^{8}$ Does not include the 13 participants who disregarded this question. 
Personal Experience With Condoms

Overall, reported previous experience with condoms was high. Females reported previously using condoms at a slightly higher rate than males. As shown in Table 5, nearly all of the females (96\%) and $90 \%$ of the males reported having previously used a condom. This difference was not statistically significant $(\mathrm{p}=.21)$. Two-thirds $(63 \%)$ of both males and females reported that it was both partners' idea to use a condom.

Table 5

Gender Differences in Experience with Condoms

\begin{tabular}{|c|c|c|c|c|c|}
\hline \multirow[b]{3}{*}{ Variable } & \multirow[b]{3}{*}{$\underline{\mathbf{n}}$} & \multicolumn{4}{|c|}{ Gender } \\
\hline & & \multicolumn{2}{|c|}{$\%$ Females } & \multicolumn{2}{|c|}{$\%$ Males } \\
\hline & & Yes & No & Yes & No \\
\hline Previous use of condoms. & 165 & 96 & 4 & 90 & 10 \\
\hline Previously talked to a partner about condom use. * & 164 & 98 & 2 & 88 & 13 \\
\hline Talking about condoms is uncomfortable. & 164 & 30 & 66 & 29 & 63 \\
\hline Sex with potential partner without a condom. * & 155 & 3 & 93 & 27 & 74 \\
\hline Plan to use a condom next time. & $1+2^{8}$ & 54 & 46 & 71 & 29 \\
\hline
\end{tabular}

Note. Values are rounded percentages and may not equal $100 \%$.

${ }^{a} 14 \%$ of the sample answered "I don't know" in response to this question.

${ }^{*} \mathrm{p}<.05$

As Table 5 demonstrates, females (98\%) reported that they had previously talked with a partner about using condoms significantly more often than males $(88 \%)$. Nearly a 
third of both males (29\%) and females (30\%) reported that talking to a partner about condoms was uncomfortable (see Table 5).

Participants were asked if they would have sex with a potential partner even if that partner did not agree to use a condom. Overall, both males and females said they would not have sex with a potential partner without condoms. However, significantly $(\mathrm{p}=$ $.00005)$ more males $(27 \%)$ than females $(3 \%)$ were willing to have sex without condoms (see Table 5).

\section{Regular Use of Condoms}

In this study, the two indicators of regular condom use were frequency of condom use over the past year (question \#26), and planning to use condoms in the future (question \#27).

Table 5 shows the response from the participants regarding their intent to use condoms in the future. Males (71\%) reported slightly more often than females $(54 \%)$ that they intend to use condoms, but this difference was not significant. Twenty three respondents ( $14 \%$ of the total sample) did not know if they would use condoms the next time they had intercourse.

The second indicator of regular condoms use, reported use over the past year, was significantly different between males and females $(\underline{p}<.05)$. Males reported higher condom use over the past year, with $51 \%$ reporting use "more than half the time" and only $33 \%$ of females reporting the same. Females were more likely to report using a condom 
for sex only "once" or "less than half the time" during the past year (see Table 6). Ageadjusted results were the same as crude results, indicating that age had no confounding effect on this gender difference.

Table 6

Use of Condoms Over the Past Year by Gender

\begin{tabular}{llcccc}
\hline & & \multicolumn{3}{c}{ Gender } \\
\cline { 3 - 5 } & $\underline{n}$ & & Females & Males \\
\hline & & \% User & \% Non-user & $\%$ User & \% Non-User \\
Use of condoms over the past year.* & 158 & 33 & 67 & 51 & 49 \\
\hline
\end{tabular}

Note. User represents a response of "more than half the time." Non-user represents a response of

"never", "once", "less than half the time", or "did not have sex during the past year."

$* \mathbf{p}<.05$

Further analysis showed significant differences between the single and non-married monogamous females who reported regular condom use (see Table 7). No differences were found between single and monogamous males.

Of the total number of females intending to use condoms at next intercourse ( $\underline{n}=$ 43), $79 \%$ were single and $21 \%$ were monogamous (see Table 7 ). This was highly significant $(\mathrm{p}<.0001)$. Among females reporting that they used condoms over the past year "more than half the time", $69 \%$ were single compared to $31 \%$ monogamous. This difference was marginally significant $(\underline{p}=.06)$. 
Table 7

Single vs. Monogamous Females and Regular Condom Use

\begin{tabular}{|c|c|c|c|}
\hline \multirow[b]{2}{*}{ Variable } & \multirow[b]{2}{*}{$\underline{\mathrm{n}}^{\mathrm{B}}$} & \multicolumn{2}{|c|}{ Relationship Status } \\
\hline & & $\%$ Single & $\%$ Monogamous \\
\hline Plan to use a condom next time. & $\overline{43}$ & 79 & 21 \\
\hline Used condoms "more than half the time." & 29 & 69 & 31 \\
\hline
\end{tabular}

"Number of females who responded "yes" to these questions.

${ }^{*} \mathbf{p}<.0001$

\section{Condom Information}

In questions \#28 and \#29, participants were asked to choose from a list of seven possible sources of condom information. Respondents were asked to choose all sources that applied. The three most common sources for "first learned about condoms" were school health services (51\%), friends (49\%), and posters and/or brochures $(28 \%)$. The sources of current condom information were similar. Respondents replied that they currently receive condom information through school health services $(63 \%)$, posters and/or brochures $(36 \%)$, and from friends (31\%). Females (73\%) responded significantly $(\mathrm{p}=.008)$ more often than males $(51 \%)$ that they currently receive condom information through school health services.

Nearly three quarters $(72 \%)$ of the students felt that they did not need to learn more about condoms. Of the $28 \%$ who felt they did need to learn more about condoms, 
16 listed preferred sources. Eight wanted to talk to health professionals, five wanted to talk to friends or to their partner about condoms, and three wanted to be able to read the information.

\section{Qualitative Responses}

Several themes emerged from analysis of the qualitative responses. Most of the comments were by students who felt that condoms protect against AIDS and STDs, and felt that to protect themselves, they should wear condoms. All of the responses to question \#25 (regarding using a condom with a potential partner) were from students who said they would not have sex with a potential partner without a condom. Most of the females commented that if a partner does not agree to use condoms, he "must not care about you" or has "something to hide." In the words of some of the females who responded that they would not have sex with a potential partner; "If he does not use it (condom) with me, he would not have used it with anybody else, that is scary", "my life is important to me", "I would have no idea what kind of disease(s) they have", and "no hat, no love."

In response to question \#31 (current method of birth control), most of the females, and several of the males, reported that they, or their partners, were on birth control pills. Others mentioned that they used condoms for birth control or other barrier methods, such as a diaphragm. Many general comments were made about the effectiveness of condoms. Some people thought they were "overrated", while some felt they should be distributed 
free to everyone who wants them. Many of the males mentioned discomfort with wearing condoms, and one male respondent wrote that he was "tired of all the talk about condoms."

Question \#27 asked participants if they thought they would use condoms the next time they had sex. Several of the open-ended responses to this question, from participants who replied that they would not use a condom the next time, were by females on birth control pills. Females were also more likely than males to report that they were in monogamous relationships and did not need to use condoms. Other responses were from males and females who had been tested for HIV along with their partners.

Forty percent of the 246 respondents wrote additional comments in part IV (personal viewpoints about condoms) of the questionnaire. The majority of these comments $(62 \%)$ were from female respondents. Overall, feelings about condoms were positive from both males and females, but different themes emerged. The females' comments were longer and $40 \%$ of them wrote about relationships, often expressing the attitude that "you do not need condoms when you are monogamous." Two of the female respondents mentioned that they needed to learn more about condoms. The males did not comment on monogamy or relationships, but instead focused on how they felt about wearing condoms. One theme that emerged from the males was that condoms were a "necessity" and that they would like to "improve" condoms so they fit better and were not as irritating. One of the responses from a male was, "They are fairly inconvenient, yet a necessary evil in today's society." 
Comments about condom education differed for males and females. Females said they would like to see more condom education in schools, but the males who discussed this were very much against it. One male respondent felt that condom distribution in high schools sends the wrong message. He associated distribution of condoms in schools with saying, "kids are going to shoot each other at school, so here's a free bulletproof jacket to wear, it'll protect you."

There were many comments in favor of condom use from both males and females. Comments from males included, "Best invention since the wheel," "Great!," and "Everyone should use them." Females were less ecstatic, but still positive with comments such as, "I am in favor of them," "Excellent for STD protection," "They're not perfect, but I like them because there are no side effects," and "They do take away from the heat of the moment, but then, so do kids or disease."

\section{Summary}

The analysis was based on a sample of 165 sexually active, single, undergraduate students. The sample was almost evenly distributed between males (44\%) and females (56\%). More than half $(65 \%)$ of the sample reported that they became sexually active between 15 and 19 years of age. Slightly more than half of the sample was white $(57 \%)$ and enrolled in a major program other than Health Science (54\%). The results indicated that college students have received their condom information from school health services, friends, and posters. Most (72\%) did not feel that they needed more information. 
Results of this study showed that males reported previously using condoms at a higher rate than females, however, the difference was not statistically significant. Males reported a more frequent use of condoms over the past year and were more likely to predict using condoms the next time they have sex. Both males and females reported that the idea to use condoms came from both partners. A large majority of the final sample felt that condoms did protect against AIDS and STDs.

Statistically significant gender differences were found in three areas regarding experience with condoms: (a) communication with a partner about condoms, (b) intent to have sex with a potential partner without a condom, and (c) reported use of condoms over the past year. Significant gender differences were also found in three statements regarding condom attitudes and knowledge: (a) decreased sexual pleasure from a condom, (b) easy to have sex on the spur of the moment with a condom, and (c) feelings that condoms are difficult to use. A significant difference was found between single and non-married monogamous females in intending to use condoms in the future. 
Chapter 5

\section{DISCUSSION AND CONCLUSIONS}

\section{Data Analysis Limitations}

In addition to the limitations discussed in Chapter 1, several limitations to the research were discovered during data analysis. These limitations may affect how the results are interpreted.

The first limitation was that many questionnaires were returned without being completely filled out by participants. Completion of the questionnaire was voluntary and self-paced, and students had the option of skipping questions they felt uncomfortable with. As a result, analysis of a few questions had to be performed on less than the 165 final responses.

Many of the students from the Engineering class completed only the first page of the questionnaire and left the second and third pages empty. This is significant, for while the first page contained demographic questions, the second and third pages covered personal activity including condom use, condom knowledge and attitudes, and sexual activity. As a result, these questionnaires were excluded from the final analysis. This limited the number of students in the final sample because respondents could not be identified as sexually active, one of the key inclusion criteria for this study.

Another limitation, discovered once questionnaires were returned, involved respondents misunderstanding or not properly reading specific questions. For example, 
many students responded to question \#7, "What county do you live in?," with "United States." Many students also appeared to misunderstand question \#30 which asks "who would you like to talk to about condoms." Respondents frequently answered with what they wanted to learn about condoms. These two misinterpretations raise the possibility that participants may have misunderstood other questions on the questionnaire.

The final sample size $(\underline{\mathrm{N}}=165)$ would be considered a limitation in an epidemiological study. However, the purpose of this research was to enhance the practice of college health education through exploring attitudes and behaviors associated with condoms. The 165 respondents were well balanced in terms of age, demographics, and college major. Moreover, they offered a range of attitudes, beliefs, and self-reported behaviors. Results are immediately applicable to the development of condom education programs for college students. In addition, these data will add to the existing literature in this field, particularly in the area of gender differences and safer sex behaviors.

\section{Discussion}

The purpose of this research was to determine if sexually active young males use condoms on a more regular basis than sexually active young females, and if so, why. Results showed that $96 \%$ of the females and $90 \%$ of the males reported previous use of condoms. Reported condom use over the past year and the intent to use a condom the next time for sex were the indicators of "regular" use of condoms. Males reported significantly higher than females on both indicators of regular condom use. 
One possible reason for the low reported regular condom use for females may be that several of the females in this sample reported using birth control pills for pregnancy prevention. Their qualitative comments suggest that college females may be more concerned about pregnancy prevention than disease prevention. It is possible that they are not informed about using condoms for disease protection by the health professional providing their birth control pills.

A second reason females did not report condom use as often as males may be because of their low self-efficacy about condoms. An indicator of self-efficacy in this study, was the statement "condoms are difficult to use." A significantly higher proportion of females than males found this question not applicable. This may indicate that females do not know how to use condoms which could result in low self-efficacy around condom use.

In the qualitative responses, several females replied that they did not use condoms because they were in monogamous relationships. Because being in a monogamous relationship came up so often from females in their qualitative responses, it seemed that this was a significant factor. Further analysis with single and non-married monogamous females showed that of the females reporting regular use of condoms, significantly more were self-identified as single. Other responses include that females had been tested for HIV, along with their "monogamous" partners, and therefore did not feel they needed to use condoms. 
Significantly more females than males reported that they were in monogamous relationships. It is interesting that many of the females said they were in monogamous relationships while most of the males said they were single. Females also were more likely to discuss their relationships in the qualitative sections, while the males did not.

Even though males appear to use condoms on a more regular basis than females, they were significantly more willing to have sex with a potential partner without a condom. Another way to look at this result is that males do not plan or intend to use condoms with a new sexual partner. It may be because they feel uncomfortable about carrying condoms with them, or expect a potential partner to be on birth control pills and thus do not feel the need to use condoms. Only $3 \%$ of the females in this study reported that they would have sex with a potential partner without a condom, even though they did not report regular use of condoms themselves.

Another reason for this finding may be that males do not feel vulnerable to contracting HIV from female sexual partners. Young males believe that it is very rare for a female to pass HIV to their male partners and, therefore, do not feel the need to use condoms (S. Lapp, personal communication, March 2, 1994). Young males also assume that a female will take the initiative to interrupt sex to suggest using a condom. This attitude of "if she doesn't care then I don't care" (J. Breny, personal communication, March 8,1994$)$ is frequent among college-aged males and may contribute to their lack of planning to use condoms with a potential partner. 
The females in this study reported a higher incidence of previous conversations with a partner about condoms. Females were also less embarrassed about talking with a partner about condoms. This may be due to differences in the socialization of males and females. Males are socialized to be less emotional than females and usually do not talk about personal feelings even to their friends. It may be that males are afraid of rejection by female partners if condom use is mentioned, which would explain why males are less willing to communicate personal feelings and concerns with a sexual partner.

Overall, females had a more favorable attitude towards condoms. Females were more likely to agree that (a) condoms make it easy to have sex on the spur of the moment, (b) condoms do not decrease sexual pleasure, (c) condoms are not embarrassing to talk about, and (d) being protected with a condom makes sex more enjoyable. Both males and females felt that condoms were an effective method of disease prevention. The majority of the sample reported that condoms would protect against ADS and other sexually transmitted diseases (STDs).

It is important to note that stratified analysis showed that Health Science majors did not report higher condom use. This finding is contrary to earlier assumptions that, since Health Science students would be more knowledgeable about safer sex because of previous coursework, they would have higher levels of condom use. Two of the Health Science courses used for data collection were human sexuality classes, but were approached early in the semester, before the presentation of condom information. 
The majority of both males and females reported that they learned about condoms through school health services and from friends. The age at which participants learned about condoms was not differentiated in the questionnaire. In hindsight, it seems important to know this information in order to analyze the point of intervention at different age levels. This information would be particularly useful to college health educators developing education programs so they are aware of what condom information students have already received. Many of the students who indicated that they needed more information about condoms said they would like to learn it from health professionals.

In summary, males reported significantly more often than females that they used condoms on a regular basis even though females had a more positive attitude about condoms. Females were more adamant about protecting themselves from a potential sexual partner than males, even though they reported using condoms less regularly and did not report they would use condoms the next time they had sex.

Females communicated more often with a partner about safer sex and tended to report being in a monogamous relationship. Relationship status was an indicator for females' use of condoms. Using birth control pills and testing negative for HIV were also factors which might explain the low reported regular use of condoms for college females. Both males and females felt that condoms effectively protected against AIDS and STDs. 


\section{Anecdotal Information}

Several interesting observations were made during data collection and data entry. Throughout the course of collecting data, condoms were available to those participants who completed questionnaires. A total of 300 condoms were purchased through the Condom Co-op on the San Jose State University campus. Most of the condoms were black, but a few of them were brightly colored. When students turned in their questionnaires, they were allowed to choose condoms to take with them. Most of the students were observed choosing the colored condoms over the black ones. In fact, when the colored condoms ran out, fewer students took condoms at all.

It was, at times, difficult to get the students to take condoms with them. It became clear that more males than females were picking up condoms. Some of the females were obviously shy about taking condoms, but many said that they had "plenty" at home and did not need more. When it was suggested that they take condoms for friends, they were more willing to take them.

Noticeably more females than males wrote comments in the open-ended sections of the questionnaire. Several of the males did write expressive comments regarding their feelings about condoms, but the females tended to write more and write more often.

\section{Implications for Research}

The results of this study indicate four research areas which will complement the existing body of research on gender differences, safer sex behaviors, and condom use. 
These areas for further research are (a) communicating with a partner about condom use, (b) inconsistent condom use behavior, (c) self-efficacy regarding condoms, and (d) racial and ethnic considerations for condom use behavior.

Further research is needed on communication between sexual partners, specifically males communicating with female partners about condoms. Qualitative interviews with college males investigating their level of comfort in talking about personal matters may reveal the obstacles experienced in talking with a partner about condoms. With male interviewers, the subjects may feel more at ease and better able to discuss areas in which they feel vulnerable communicating personal feelings. Results of these studies would be very useful to health educators in safer sex interventions with college males.

A second area of further research involves the reasons behind the inconsistent use of condoms among college males and females. In this study, there was a discrepancy between college males' current use of condoms and plans to use condoms in the future. It would be useful to conduct pre- and post-interviews with males to determine if condoms were used with a new partner and the reasons why or why not. Telephone interviews would be most effective since they are somewhat anonymous, can accommodate large study samples, and have high response rates.

Females were also inconsistent in their practice and philosophy of condom use. College females do not plan on having sex with a new partner without condoms and feel comfortable talking about condoms with a sexual partner even though they do not use condoms regularly. Females who reported being in monogamous relationships were 
significantly less likely to use condoms than single females. Also, being on birth control pills or having been HIV-tested were other reasons females did not feel the need to use condoms for disease protection.

Future research should look closely at why college females are not using condoms on a regular basis even though they say that they are comfortable talking about them. Qualitative case study research may reveal the reasons behind these important inconsistencies.

Research is also needed in the area of self-efficacy and competence in actual condom use. Condoms can be difficult to use. This study did not explore in detail exactly what was felt by the sample regarding this attitude. However, it is likely that if a person feels incompetent using condoms, he or she is unlikely to use them. Interviews with college students asking them about their competence in using condoms would be useful in determining where the difficulty is felt in condom use among this population.

Finally, an area that was not included in this study was that of cultural and ethnic barriers to using condoms. The findings suggest that many young people receive their safer sex education through school health services. These services may not be available to all young people. Research on sources of condom information among a more diverse sample will be very important. In addition, research on condom attitudes and behaviors of ethnically diverse college students is essential for appropriate educational interventions.

It appears that the next step in research on gender differences and safer sex behaviors should be qualitative. There is sufficient quantitative research indicating that 
males use condoms more regularly than females. Quantitative studies work well with large populations in identifying significant statistical differences and distributions.

However, to better understand the reasons behind gender differences in condom use and attitudes, researchers must study individual accounts in much greater detail. Future research should inciude open-ended, individual interviews to allow this closer look at the psycho-social dynamics surrounding condom use for men and women.

\section{Implications for College Health Education Practice}

Important gender-related trends have emerged from these data that can be used when working with males and females. This study, and others, indicate that genderspecific interventions need to be developed in order to work with the individual needs of males and females. The results of this study can be used by college health educators to help them provide more effective safer sex and reproductive health education for their students. Interventions should include the following areas: (a) communicating with sexual partners, (b) condom efficacy, (c) gender role differences, (d) utilizing school health services and the media for condom campaigns, and (e) assertiveness training.

Females in this study indicated not seeing the need to use condoms while being protected against pregnancy from birth control pills. Programs for females need to take into consideration that single women are using birth control pills and feel comfortable with that as their only method of protection. Health education programs for females should focus on the disease protection a condom provides and that it is necessary to use condoms 
with a partner even when using birth control pills. This intervention may need to begin by educating reproductive health professionals such as physicians, nurse practitioners, and family planning counselors. These professionals must talk about condoms when they prescribe birth control to their young patients, especially college heaith service practitioners.

This study indicated that females are more likely to talk about their relationships and think of themselves as monogamous. Females who considered their relationship to be monogamous, did not feel the need to use condoms. As much as this may be the case, some of them may not realize that their male partner does not consider himself to be monogamous. The males in this study did not report being in monogamous relationships and did not refer to relationship status as a determinant of condom use. Communication trainings for talking with a new sexual partner, would help males and females feel comfortable discussing issues such as condom use.

These results showed that females are comfortable talking with their partners about condoms. Health educators can reinforce this by emphasizing that females initiate conversations about condoms. Research shows that females are better communicators in personal situations than males and are more comfortable talking about their feelings. By engaging clients in role playing activities with males and females, communicating with a sexual partner becomes easier.

Health education programs for males need to be aimed at helping them communicate with their female partners about safer sex. As mentioned above, males are 
less inclined than females to discuss personal feelings with other people. Health educators can assist young males through role plays, case studies, and one-on-one counseling sessions. As males gain confidence in their communication skills their planning for, talking about, and intending to use condoms will increase. Males need to learn not to assume that their partners are on birth control pills or to wait for their partners to bring up the subject of condoms but to initiate the conversation themselves.

Assertiveness training for both males and females would be helpful in addition to programs aimed at improving communication between genders. Knowing how to communicate is only half of what is needed by young people engaging in a new relationship. College students need to know that it is okay to initiate conversations about safer sex and to be assertive when they see an opportunity to discuss sexual behaviors.

It is also important to know that more than half of this sample received their condom information from college health services. College health educators can use this information as a reason to provide more information on college campuses. Many students receive all of their health care from on-campus clinics and these locations are ideal for distributing condom-related materials. Health education messages and condom information should be made available in all locations of a college campus where students spend a lot of time. Libraries, gymnasiums, classrooms, and student unions are ideal locations for safer sex health fairs, information giveaways, and free condom distribution. Health education programs should look into gender role theory, differences in the socialization of males and females, and the indicators of condom use in developing criteria 
for safer sex interventions. It seems that effective interventions will be gender-specific, and will need to include role playing exercises on how to communicate with partners and negotiate condom use as discussed above. Knowing where and when students first learned about condoms can assist educators in designing appropriate programs based on previous knowledge.

Finally, media campaigns can be incorporated in many of the above interventions. For example, campaigns showing males talking about condoms and initiating conversations, commercials showing females carrying condoms and discussing the positive aspects of condoms, and males and females talking with each other about the effectiveness of condoms are all ways to promote condom use. The media is a very effective and widely used tool for educational campaigns with young people.

This study indicates the need for research and health education programs focusing on college students and condom use. Sexually transmitted diseases, unwanted pregnancies, and now AIDS are rampant among our young people. As health care professionals, we need to focus on educating young people to protect themselves from illness and disability. For the health of our future and for society, research and interventions in the area of safer sex behaviors for young adults are critical. 


\section{REFERENCES}

Baldwin, J. D., \& Baldwin, J. J. (1988). Factors affecting ADS-related sexual risktaking behavior among college students. The Journal of Sex Research, 25, 181-196.

Bandura, A. (1977). Self-efficacy: Toward a unifying theory of behavioral change. Psychological Review, 84, 191-215.

Bandura, A. (1989). Perceived seif-efficacy in the exercise of control over AIDS infection. In Mays, V. M., Aibee, G. W., \& Schneider, S. F. (Eds.), Primary prevention of AIDS: Psychological approaches (pp. 128-141). Newbury Park, CA: Sage.

Basen-Engquist, K. (1992). Psychosocial predictors of "safer sex" behaviors in young adults. AIDS Education and Prevention, 4(2), 120-134.

Bell, T. A., \& Holmes, K. K. (1984). Age-specific risks of syphilis, gonorrhea, and hospitalized pelvic inflammatory disease in sexually experienced U.S. women. Sexually Transmitted Diseases, 11, 291-295.

Boyer, C. B., \& Kegeles, S. M. (1991). AIDS risk and prevention among adolescents. Social Science and Medicine, 33, 11-23.

Brafford, L. J., \& Beck, K. H. (1991). Development and validation of a condom selfefficacy scale for college students. Journal of American College Health, 39(5), 219225 .

Brien, T. M., Thomas, D. L., Mahoney, C. A., \& Wallnau, L. (1994). Dimensions of selfefficacy among three distinct groups of condom users. Journal of American College Health, $\underline{42}, 167-174$.

Burger, J. M., \& Inderblitzen, H. M. (1985). Predicting contraceptive behavior among college students: The role of communication, knowledge, sexual anxiety, and selfesteem. Archives of Sexual Behavior, 14, 343-350.

Carroll, L. (1991). Gender, knowledge about AIDS, reported behavioral change, and the sexual behavior of college students. Journal of American College Health, $\underline{40}, 5-12$. 
Catania, J. A. (1989). Predictors of condom use and multiple partnered sex among sexually active adolescent females: Implications for AIDS-related health interventions. Journal of Sex Research, 26, 514-524.

Centers for Disease Control and Prevention. (1993, December). HIV/AIDS Surveillance Report. Washington, DC: Department of Health and Human Services.

Collins, J., Holtzman, D., Kann, L., \& Kolbe, L. (1993, October). Predictors of condom use among U.S. high school students. Paper presented at the American Public Health Association Annual Meeting, San Francisco, CA

Conant, M. A., Spicer, D. W., \& Smith, C. D. (1984). Herpes simplex virus transmission: Condom studies. Sexually Transmitted Diseases, 11, 94-95.

Covin, J., Lovato, C., Patrick, K., \& Donovan, M. (1993, October). Assessment of HIV/AIDS risk behaviors and prevention effects among college youth. Paper presented at the American Public Health Association Annual Meeting, San Francisco, CA.

Dean, A. G., Dean, J. A., Burton, A. H., \& Dicker, R. C. (1990). Epi Info, Version 5: A word processing, data base, and statistics program for epidemiology on microcomputers [Computer program]. Stone Mountain, GA: USD, Incorporated.

DeBuono, B. A., Zinner, S. H., Daamen, M., \& McCormack, W. M. (1990). Sexual behavior of college women in 1975, 1986, and 1989. The New England Journal of Medicine, $\underline{322}, 821-825$.

DiClemente, R. J. (1990). The emergence of adolescents as a risk group for Human Immunodeficiency Virus infection. Journal of Adolescent Research, $\underline{5}, 7-17$.

DiClemente, R. J., Durbin, M., Siegel, D., Krasnovsky, F., Lazarus, N., \& Comacho, T. (1992). Determinants of condom use among junior high school students in a minority,

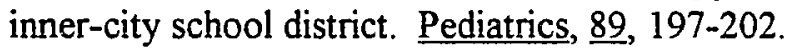

Division of STD/HIV Prevention. (1992, July). Sexually Transmitted Disease Surveillance. U.S. Department of Health and Human Services, Public Health Service. Atlanta, GA: Certers for Disease Control.

Eagly, A. H., \& Steffen. V. J. (1984). Gender stereotypes stem from the distribution of women and men into social roles. Journal of Personality and Social Psychology, 46, 735-754. 
Elfenbein, D. S., Weber, F. T., \& Grob, G. (1991). Condom usage by a population of delinquent southern adolescents. Journal of Adolescent Health, 12, 35-37.

Feldblum, P. J., \& Fortney, J. A. (1988). Condoms, spermicides, and the transmission of Human Immunodeficiency Virus: A review of the literature. American Journal of Public Health, $\underline{78}, 52-53$.

Gayle, H. D., Keeling, R. P., Garcia-Tunon, M., Kilbourne, B. W., Narkunas, J. P., Ingram, F. R., Rogers, M. F., \& Curran, J. W. (1990). Prevalence of the Human Immunodeficiency Virus among university students. The New England Journal of Medicine, 323, 1538-1541.

Goldman, J. A., \& Harlow, L. L. (1993). Self-perception variables that mediate AIDSpreventive behavior in college students. Health Psychology, 12, 489-498.

Hawkins, M. J., Hawkins, W. E., Ellis, B., \& Ryan, E. (1993, October). Reported safer sex behaviors within a random sample of college students. Paper presented at the American Public Heaith Association Annual Meeting, San Francisco, CA.

Hodges, B. C., Leavy, M., Swift, R., \& Gold, R. S. (1992). Gender and ethnic differences in adolescents' attitudes toward condom use. Journal of School Health, 62, 103-106.

Holmes, V., \& Fernandez, F. (1988). HIV in women: Current impact and future implications. The Female Patient, $\underline{13}, 47-54$.

Joffe, A., \& Radius, S. M. (1993). Self-efficacy and intent to use condoms among entering college freshman. Journal of Adolescent Health, 14, 262-268.

Keller, M. J. (1993). Why don't young adults protect themselves against sexua! transmission of HIV? Possible answers to a complex question. AIDS Education and Prevention, 5, 220-233.

Koop, C. E. (1986). Surgeon General's report on Acquired Immune Deficiency Syndrome. Washington, DC: U.S. Department of Health and Human Services.

Leland, M. L., \& Barth, R. D. (1992). Gender differences in knowledge, intentions, and behaviors concerning pregnancy and sexually transmitted disease prevention among adolescents. Journa! of Adolescent Health, 13, 589-599. 
MacDonald, N. E., Wells, G. A., Fisher, W. A., Warren, W. K., King, M. A., Doherty, J. A., \& Bowie, W. R. (1990). High-risk STD/HIV behavior among college students. The Journal of The American Medical Association, 263, 3155-3159.

Manning, D., Balson, P. M., Barenberg, N., \& Mizell Moore, T. (1989). Susceptibility to AIDS: What college students do and don't believe. Journal of American College Health, $\underline{38}, 67-73$.

O'Leary, A., Goodhart, F., Jemmott, L. S., \& Boccher-Lattimore, D. (1992). Predictors of safer sex on the college campus' A social cognitive theory analysis. Journal of American College Health, 40, 254-263.

Oliver, M. B., \& Hyde, J. S. (1993). Gender differences in sexuality: A meta-analysis. Psychological Bulletin, 114, 29-51.

Orr, D. P., Langefield, C. D., Katz, B. P., Caine, V. A., Dias, P., Blythe, M., \& Jones, R. B. (1992). Factors associated with condom use among sexually active female adolescents. The Journal of Pediatrics, $120,311-317$.

Perry, C. L., Baranowski, T., \& Parcel, G. S. (1991). How individuals, environments, and health behavior interact: Social Learning Theory. In K. Glanz, F. M. Lewis, \& B. K. Rimer (Eds.), Health Behaviors and Health Education: Theory, Research, and Practice (pp. 161-186). San Francisco: Jossey/Bass.

Petosa, R., \& Jackson, K. (1991). Using the Health Belief Model to predict safer sex intentions among adolescents. Health Education Quarterly, 18, 463-476.

Radius, S. M., Joffe, A., \& Gall, M. J. (1991). Barrier versus oral contraceptive use: A study of female college students. The Joumal of American College Health, $\underline{40}$ (2), 8385.

Rickert, V. I., Gottleib, A., \& Jay, M. S. (1990). A comparison of three clinic-based AIDS education programs on female adolescents' knowledge, attitudes, and behavior. Journal of Adolescent Health Care, 11, 298-303.

Rickert, V. I., Jay, S., Gottleib, A., \& Bridges, C. (1989). Adolescents and AIDS: Female's attitudes and behaviors toward condom purchase and use. Journal of Adolescent Health Care, 10, 313-316.

Rosenstock, I. M. (1991). The Health Belief Model: Explaining health behavior through expectancies. In K. Glanz, F. M. Lewis, \& B. K. Rimer (Eds.). Health Behavior and 
Health Education: Theory, Research, and Practice (pp. 39-62). San Francisco: Jossey-Bass.

Rosner, B. (1990). Fundamentals of Biostatistics (3rd ed.). Boston: PWS-KENT.

Sacco, W. P., Rickman, R. L., Thompson, K., Levine, B., \& Reed, D. L. (1993). Gender differences in AIDS-relevant condom attitudes and condom use. AIDS Education and Prevention, 5, 311-326.

San Francisco Department of Public Health. (1992). Sexually Transmitted Disease Update for HIV Service Providers in San Francisco. San Francisco, CA.

Tanfer, K., Grady, W. R., Klepinger, D. H., \& Billy, J. O. G. (1993). Condom use among U.S. Men, 1991. Family Planning Perspectives, 25, 61-66.

Turner, J. C., Korpita, E., Mohn, L. A., \& Hill, W. B. (1993). Reduction in sexual risk behaviors among college students following a comprehensive health education intervention. The Journal of American College Health, 41, 187-193.

Valdiserri, R. O., Arena, V. C., Proctor, D., \& Bonati, F. A. (1989). The relationship between women's attitudes about condoms and their use: Implications for condom promotion programs. American Journal of Public Health, 79, 499-501.

Wilson, T. E., Jaccard, J., Endias, R., \& Minkoff, H. (1993). Reducing the risk of HIV infection for women: An attitudinal analysis of condom-carrying behavior. Journal of Applied Social Psychology, 23, 1093-1110.

Wulfert, E., \& Wan, C. K. (1993). Condom use: A self-efficacy model. Health Psychology, 12, 346-353.

Yesmont, G. H. (1992). The relationship of assertiveness to college students' safer sex behaviors. Adolescence, 27, 253-272. 
APPENDIX A QUESTIONNAIRE 
Attitudes, Beliefs, and Behaviors About the Use of Condoms Among College Students

Part I: Personal Information

Please answer the following general questions about yourself. Indicate only one response to each question:

1. How old are you? $\quad 15-19-20-24-\quad 25-29$

30-34- 35-39- $40+$

2. Are you male _ or female __ ?

3. What year are you in at school?

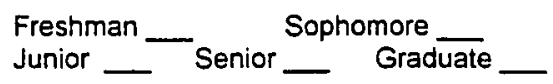

4. Is Health Science your major? yes __ no

5. Are you in a sorority or fratemity at SJSU? yes _ no _

6. What are your living arrangements?

Live on campus ___ Live with parents ___ Live off campus alone

Live with spouse/partner __ Share an apartment with friends

7. What county do you live in?

8. How would you describe your ethnic/cultural background?

African-American White (non-Hispanic)

Native American
Asian/Pacific Islander

Hispanic/Latino

Other (describe if you want)

9. What is your relationship status?
Single
Married
In a monogamous relationship
Divorced

\section{Part II: Condom Knowledge and Attitudes}

Please respond to the statements below as honestly as possible. For each sentence, choose the most appropriate response for you from the selection on the right. Check ( $)$ only one response for each statement. All statements refer to latex condoms only.

Condoms...

10...are used and accepted by many people my age.

\begin{tabular}{|c|}
\hline $\begin{array}{c}\text { strongly } \\
\text { agree }\end{array}$ \\
\hline
\end{tabular}


Condoms..

11...make it easy to have sex on the spur of the moment.

12...can be used without having to see a doctor for a prescription.

13...help me to enjoy sex more because I know l'm protected.

14...protect me from getting AIDS and other sexually transmitted diseases.

15... are too embarrassing to buy

16...decrease my sexual pleasure.

17...are difficult for me to use

18...in my opinion, are the most effective method of birth control.

19... are embarrassing to talk about.

20... do not protect me from getting a disease.

\section{Part III: Personal Activity}

Please answer the following questions as honestly as possible Remember, this is an anonymous questionnaire. There is no way your responses can be identified with you, and you may choose not to answer any question.

21. Have you ever had sexual intercourse?

If yes, how old were you the first time:

strongly

agree

$\square$

$\square$

$\square$

$\square$

$\square$ agree

not

applicable

disagree

strongly

disagree

$\square$

$\square$


25. If a potential partner did not agree to use a condom for sex, would you have sexual intercourse with that person anyway?

yes _ no w w w w w w w not?

26. During the past year, if you have had sexual intercourse, how often did you or your partner wear a condom?

never ___ once __ less than half the time

more than half the time did not have sex during the past year

27. The next time you have sex, do you think that you or your partner will use a condom?

yes _ no _ don't know __ why or why not?

28. From whom did you first learn about condoms? (Check all that apply)

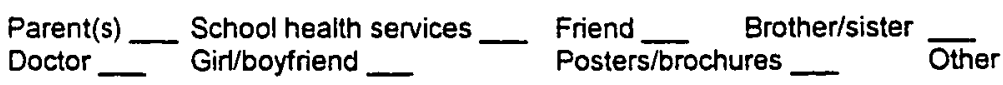

29. Where do you get condom information from now? (Check all that apply)

Parent(s) _ School health services __ Friend ___ Brother/sister

Doctor _ Girl/boyfriend Posters/brochures _ Other

30. Do you feel that you need to leam more about condoms? yes __ no

If yes, who would you like to talk to about condoms?

31. If you are in a relationship now, do you or your partner use any form of birth control (i.e. pills, diaphragm, Norplant)?

yes __ no __ If yes, please describe

32. How would you describe your sexual identity?

Heterosexual B__ Bisexual

Homosexual Don't know

Part IV: Personal Viewpoints

Please use this space to comment, add, or express your feelings about condoms.

Thank you for your time and cooperation! 
APPENDIX B

SJSU HUMAN SUBJECTS-INSTITUTIONAL REVIEW BOARD ACCEPTANCE LETTER 
TO: Jean M. Breny Bontempi 646 Cole street, \#6 San Francisco, CA 94117

FROM :

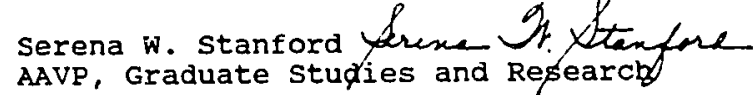

DATE: $\quad$ September 29,1993

The Human Subjects-Institutional Review Board has approved your request to use human subjects in the study entitled:

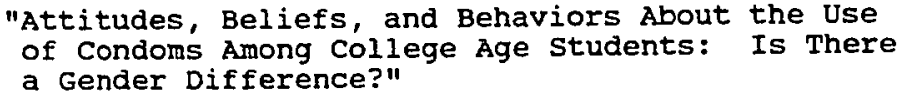

This approval is contingent upon the subjects participating in your research project being appropriately protected from risk. This includes the protection of the anonymity of the subjects' identity when they participate in your research project, and with regard to any and all data that may be collected from the subjects. The Board's approval includes continued monitoring of your research by the Board to assure that the subjects are being adequately and properly protected from such risks. If at any time a subject becomes injured or complains of injury, you must notify Dr. Serena stanford immediately. Injury includes but is not limited to bodily harm, psychological trauma and release of potentially damaging personal information.

Please also be advised that each subject needs to be fully informed and aware that their participation in your research project is voluntary, and that he or she may withdraw from the project at any time. Further, a subject's participation, refusal to participate or withdrawal will not affect any services the subject is receiving or will receive at the institution in which the research is being conducted.

If you have any questions, please contact me at (408) 924-2480.

$$
\text { Gizaroval is granted from 9/29/93-9/28/94 }
$$


APPENDIX C

CONSENT FORM 
College of Applied Sciences and Arts - Ospartment of Health Science

One Wasningion Square • San Jose. Calltornia 95192-0.052 • 4081924.2970

\section{Agreement to Participate in Research}

Responsible Investigator: Jean M. Breny Bontempi

Title of Protocol: Attitudes, Beliefs, and Behaviors About the Use of Condoms Among College Students: Is There a Gender Difference?

I have been asked to paricipate in a research study investigating college students' beliefs, behaviors, and attitudes about condoms. I will be asked to answer an anonymous questionnaire administered by the Principal Investigator named above. Some of the questions are personal and very sensitive and I may choose to answer or not answer any question. The survey will take no longer than twenty minutes to complete. It will be administered in my classroom and collected by the investigator upon completion.

There are no foresecable risks, discomforts, or discernible benefits if I choose to participate in this study. I understand that participation is voluntary and if I choose not to participate it will not affect my reputation at SISU in any way. If I decide to participate in this study I understand that I am free to withdraw at any time and I am not required to answer all the questions if I do not choose to do so.

The results of this study may be published in the future but no information that could identify my as a subject will be used. I, therefore, release the investigator to publish any results of the study. There will be no compensation for participating in this study, however, the investigator will provide a safer sex workshop upon completion of the questionnaire.

Any questions about the research may be directed to Jean M. Breny Bontempi, Principal Investigator, at (415) 255-7211. Complaints about the research may be presented to William Washington, Dr. P.H., Chair of the Department of Health Science, at (408) 924-2970. Questions or complaints about research, subjects' rights, or research-related injury may be presented to Serena Stanford, Ph.D., Associate Academic Vice President for Graduate Studies and Research, at (408) 924-2480.

I agree to participate in this research. I have received a signed and dated copy of this consent form

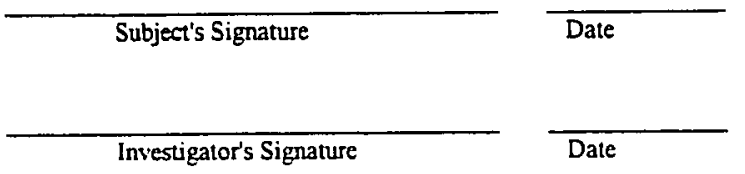

- The signature of a subject on this document indicates agreement to participate in the study.

- The signature of a researcher on this document indicates agreement to include the above oamed sabject in the research and attestation that the subject has been fully informed of her or bis rights. 
APPENDIX D

CODE BOOK 


\title{
CODE BOOK
}

Attitudes, Beliefs, and Behaviors About Condoms

Among College Students

\author{
Jean M. Breny Bontempi \\ File name: Condom.REC
}

\section{Question}

Code

Variable

Class Type

$$
\begin{aligned}
& 1=\text { Rø, F93, Stress } \\
& 2=\text { Perales, F93, HS140 } \\
& 3=\text { Roe, F93,HS104 } \\
& 4=\text { Sermon, F93, Writing } \\
& 5=\text { Pies, S94, HS140 } \\
& 6=\text { Roe, S94, HS104 } \\
& 7=\text { Kovarik, S94, HS } \\
& 8=\text { Williamson, S94, ENG }
\end{aligned}
$$

CLTYPE

Part I: Personal Information

1. How old are you?

$$
\begin{aligned}
& 1=15-19 \text { years old } \\
& 2=20-24 \\
& 3=25-29 \\
& 4=30-34 \\
& 5=35-39 \\
& 6=40+ \\
& =\text { Blank/ No answer }
\end{aligned}
$$

2. Are you

$M=$ Male

$\mathbf{F}=$ Female

3. What year are you in at school?

. = Blank

$1=$ Freshman

2 = Sophomore

$3=$ Junior

$4=$ Senior

$5=$ Graduate

$9=$ Other

. = Blank/ No answer

4. Is Health Science your major?

$1=$ Health Science

$2=$ Not Health Science

. = Blank/ No answer

5. Are you in a sorority or fraternity at SISU?

$$
\begin{aligned}
& 1=\text { Yes } \\
& 2=\text { No } \\
& \text { = Blank/ No answer }
\end{aligned}
$$

SEX

MAJOR

AGE

YEAR

FRSOR 
6. What are your living arrangements?

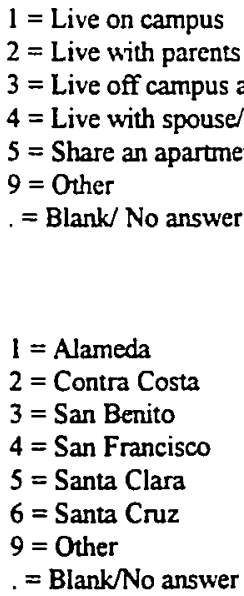

LIVING

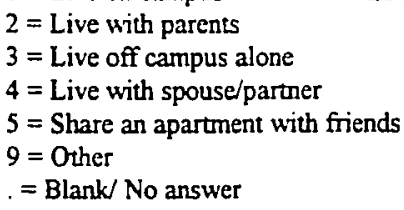

7. What county do you live in?

$$
\begin{aligned}
& 2=\text { Contra Costa } \\
& 3=\text { San Benito } \\
& 4=\text { San Francisco } \\
& 5=\text { Santa Clara } \\
& 6=\text { Santa Cruz } \\
& 9=\text { Other } \\
& \text { = Blank/No answer }
\end{aligned}
$$

8. How would you describe your ethnic/cultural background?

9. What is your relationship status?
$1=$ African-American

ETHN

$2=$ Asian $/$ Pacific Islander

$3=$ White (non-Hispanic)

$4=$ Hispanic/Latino

$5=$ Native American

$9=$ Other

. = Blank/No answer

$1=$ Single

2 = In a monogamous relationship

$3=$ Married

$4=$ Divorced

$9=$ Other

$=$ Blank/No answer

Part II: Condom Knowledge and Attitudes

Condoms...

10...are used and accepted by many people my age

11...make it easy to have sex on the spur of the moment.

12 ...can be used without having to see a
$5=$ strongly agree

$4=$ agree

$3=$ not applicable

2 = disagree

1 = strongly disagree

= Blank/ No answer
CDMACC

CDMSPR

CDMMD 
doctor for a prescription.

13...help me to enjoy sex more because I

CDMENJ

know I'm protected

14...protect me from getting AIDS and

CDMPRT

other sexually transmitted diseases.

CDMBUY

15 ... are too embarrassing to buy.

CDMDEC

16...decrease my sexual pleasure.

CDMDIF

17... are difficult for me to use.

CDMBC

18...in my opinion. are the most effective method of birth control.

CDMTLK

19...are embarrassing to talk about.

CDMDIS

20 .. do not protect me from getting a disease.

Part HII: Persanal Activity

21. Have you ever had sexual intercourse?

$$
\begin{aligned}
& 1=\text { Yes } \\
& 2=\text { No } \\
& \text { = Blank/ No answer }
\end{aligned}
$$

SEXINT

If yes, how old were you the first time:

$1=$ under 15

AGE1ST

$2=15-19$

$3=20-24$

$4=25-29$

$5=30-34$

$6=35+$

$8=$ Not applicable ("no" to above)

. = Blank/No answer

22. Have you, or your partner, ever used a condom?

$1=y$ yes

PRVUSE

2 = no

. = Blank/ No answer

If yes, how old were you the first time:

$1=$ under 15
$2=15-19$
$3=20-24$
$4=25-29$
$5=30-34$
$6=35+$
$8=$ Not applicable ("no" to above)
.$=$ Blank/ No answer

AGEUSE 
23. If you or your partner have used a condom, whose idea was it?

24. Have you ever talked about using a condom with a partner?

If yes, was it uncomfortable?

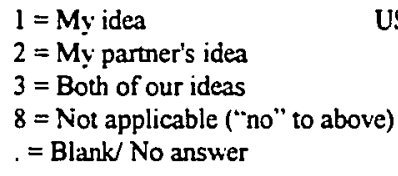

USEIDE

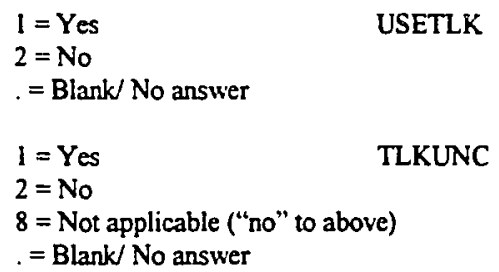

USETLK

TLKUNC

WHY

$1=$ Yes

POTSEX

$2=$ No

. = Blank/ No answer

WHY

26. During the past year, if you have had sexual intercourse, how often did you or your partner wear a condom?

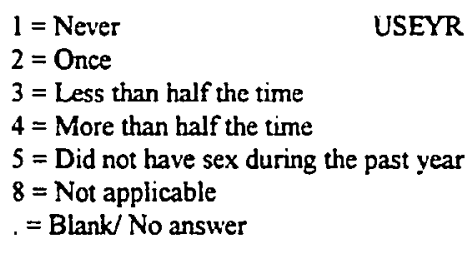

. = Blank/No answer

USEYR

25. If a potential partner did not agres to use a condom for sex, would you have sexual intercourse with that person anyway?

27. The next time you have sex, do you think that you or your partner will use a condom?

r

USENXT

$2=$ No

$3=$ Don't know

. = Blank/ No answer

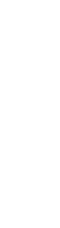


28. From whom did you first leam about condoms? (Check all that apply)

$\begin{array}{lll}\begin{array}{l}\text { Parent(s) } \\ \text { School health services }\end{array} & \text { LRNPAR } \\ \text { Friend } & \text { Yes (checked) =Y, } & \text { LRNSCH } \\ \text { Brother/sister } & \text { No (blank) = N } & \text { LRNSIB } \\ \text { Doctor } & & \text { LRNDOC } \\ \text { Girl/boyfriend } & & \text { LRNLOV } \\ \text { Posters/brochures } & \text { LRNPST } \\ 9=\text { Other } & \\ .=\text { Blank/ No answer } & \end{array}$

29. Where do you get condom information from now? (Check all that apply)

$\begin{array}{ll}\text { Parent(s) } & \\ \text { School health services } & \\ \text { Friend } & \text { Yes (checked) }=\text { Y, } \\ \text { Brother/sister } & \text { No (blank) }=\mathrm{N} \\ \text { Doctor } & \\ \text { Girlboyfriend } & \\ \text { Posters/brochures } & \\ 9=\text { Other } & \\ \text { = Blank/ No answer } & \end{array}$

NOWPAR

NOWSCH

NOWFRN

NOWSIB

NOWDOC

NOWLOV

NOWPST

30. Do you feel that you need to leam more about condoms?

$$
\begin{aligned}
& 1=\text { Yes } \\
& 2=\text { No } \\
& \text { = Blank/ No answer }
\end{aligned}
$$

NDEDUC

EDWHO

31. If you are in a relationship now, do you or your partner use any form of birth control?

$$
\begin{aligned}
& 1=\text { Yes } \\
& 2=\text { No } \\
& =\text { Blank/ No answer }
\end{aligned}
$$

BCNOW

32. How would you describe your sexual identity?

$$
\begin{aligned}
& 1=\text { Heterosexual } \\
& 2=\text { Bisexual } \\
& 3=\text { Homosexual } \\
& 4=\text { Don't know } \\
& =\text { Blank } / \text { No answer }
\end{aligned}
$$

